\title{
Article
}

\section{An Effective Method for Parameter Estimation of a Solar Cell}

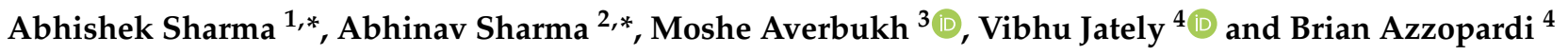 \\ 1 Department of Research and Development, University of Petroleum and Energy Studies, \\ Dehradun 248007, India \\ 2 Department of Electrical and Electronics Engineering, School of Engineering, \\ University of Petroleum and Energy Studies, Dehradun 248007, India \\ 3 Department of Electrical and Electronics Engineering, Ariel University, Ariel 40700, Israel; mosheav@ariel.ac.il \\ 4 Institute of Engineering and Transport, Malta College of Arts, Science and Technology (MCAST), \\ Paola PLA9032, Malta; vibhu.jately@mcast.edu.mt (V.J.); brian.azzopardi@mcast.edu.mt (B.A.) \\ * Correspondence: abhishek_sharma@ddn.upes.ac.in (A.S.); abhinav.sharma@ddn.upes.ac.in (A.S.)
}

check for

updates

Citation: Sharma, A.; Sharma, A.; Averbukh, M.; Jately, V.; Azzopardi, B. An Effective Method for Parameter Estimation of a Solar Cell. Electronics 2021, 10, 312. https://doi.org/ 10.3390/electronics10030312

Academic Editor: Taha Selim Ustun Received: 31 December 2020

Accepted: 22 January 2021

Published: 28 January 2021

Publisher's Note: MDPI stays neutral with regard to jurisdictional claims in published maps and institutional affiliations.

Copyright: (C) 2021 by the authors. Licensee MDPI, Basel, Switzerland. This article is an open access article distributed under the terms and conditions of the Creative Commons Attribution (CC BY) license (https:// creativecommons.org/licenses/by/ $4.0 /)$.

\begin{abstract}
Parameter extraction of the photovoltaic cell is a highly nonlinear complex optimization problem. This article proposes a new hybrid version of whale optimization and particle swarm optimization algorithm to optimize the photovoltaic cell parameters. The exploitation ability of particle swarm optimization with adaptive weight function is implemented in the pipeline mode with a whale optimization algorithm to improve its exploitation capability and convergence speed. The performance of the proposed hybrid algorithm is compared with six different optimization algorithms in terms of root mean square error and rate of convergence. The simulation result shows that the proposed hybrid algorithm produces not only optimized parameters at different irradiation levels (i.e., $1000 \mathrm{~W} / \mathrm{m}^{2}, 870 \mathrm{~W} / \mathrm{m}^{2}, 720 \mathrm{~W} / \mathrm{m}^{2}$, and $630 \mathrm{~W} / \mathrm{m}^{2}$ ) but also estimates minimum root mean square error even at a low level of irradiations. Furthermore, the statistical analysis validates that the average accuracy and robustness of the proposed algorithm are better than other algorithms. The best values of root mean square error generated by the proposed algorithm are $7.1700 \times 10^{-4}$ and $9.8412 \times 10^{-4}$ for single-diode and double-diode models. It is observed that the estimated parameters based on the optimization process are highly consistent with the experimental data.
\end{abstract}

Keywords: photovoltaic; parameter extraction; single-diode model; double-diode model; swarm intelligence

\section{Introduction}

The depletion of fossil fuel resources and resulting environmental impact due to their usages embarks the need for alternate energy resources [1]. Solar energy is one of the most promising alternative sources for fossil fuel. The free access to the energy of sunlight can be extracted employing the photovoltaic (PV) panels. The rapid adoption of solar energy by the domestic and industrial sector makes it a vital source to be explored [2] Despite the very low operational and maintenance cost, there are various limitations for efficient energy generation. An enormous amount of research has been performed and carried out to better the power output from the PV panels [3,4]. The major limitation in the execution and implementation of the solar PV power plants is the very high capital cost for installation [5]. PV cells are having nonlinear current-voltage (I-V) and power-voltage $(\mathrm{P}-\mathrm{V})$ characteristics curves with some operational limitations [6]. This non-linearity makes it difficult for any probability and approximation to increase efficiency. Every PV panel can operate at maximum efficiency, as defined by the manufacturer, only if the practical parameters (voltage-current) are somewhat close to or coinciding with the maximum power point (MPP). The real behaviour of PV panels rather different from the optimal conditions, due to the non-linearity of I-V characteristics of solar cells makes it essential to determine the MPP in each moment. It could be done through simulation techniques for better operational efficiency [7]. This technology is ensured by the model of the equivalent 
circuit having several inherent parameters. However, the parameters provided by the PV panel manufacturer don't specify the model parameters. The given information states the open-circuit voltage $\left(\mathrm{V}_{\mathrm{oc}}\right)$, short circuit current $\left(\mathrm{I}_{\mathrm{Sc}}\right)$, and current at maximum power point $\left(\mathrm{I}_{\mathrm{mpp}}\right.$ ) under standard test conditions (i.e., $1000 \mathrm{~W} / \mathrm{m}^{2}, 25^{\circ} \mathrm{C}$ ). The practical parameters vary at every instant with a change in weather conditions. The aging effects of PV also alter the parameters of the equivalent circuit $[3,8,9]$.

The core unit of the PV system is a solar cell, and it is of utmost priority to extract the parameters for a close analysis of the PV panel performance around its MPP. The simulation study of cells combined all together give the performance analysis of entire PV panels $[8,10]$. The equivalent circuit for the single- and double-diode model for parameter extraction is the recent and most widely used approach. The method of parameter extraction can be bifurcated into two major categories: analytical and optimization methods [11-15]. Although the analytical methods are the simplest and yields result quickly, but it misses the accuracy under normal day conditions with variable lighting. The deterministic ways of parameter extraction such as Newton-Raphson, nonlinear least square, Lambert Wfunctions [16], iterative curve fitting [17], conductivity method [18] and the LevenbergMarquardt algorithm [19] have many boundaries such as continuity, differentiability, and convexity related to objective functions. The boundary conditions further impose limitations on the usage of the above analytical methods, as they obtain local minima when dealing with multi-modal problems. Thus, analytical methods are not suitable to extract the parameters.

To get more accurate and precise parameters from nonlinear implicit equations with high accuracy, evolutionary algorithms [20] were proposed. The bio-related algorithms are more accurate and powerful optimization algorithms to simplify nonlinear transcendental equations as it doesn't include complex mathematics. Although, researchers have developed number of metaheuristic algorithm but there is no algorithm that provides optimal solution to all sets of problems which has also been proven by No free lunch theorem. This has motivated researchers to design new algorithms to efficiently solve complex science and engineering problems. A gradient-based optimizer (GBO) [20] inspired from the gradient-based Newton's method, Harris-Hawk optimizer (HHO) [21] inspired from cooperative behavior and chasing style of the Harris Hawks Heap-based optimizer (HBO) [22] inspired from corporate rank hierarchy and slime mould algorithm (SMA) [23] inspired from diffusion and foraging conduct of slime mould are some of the recently developed metaheuristic algorithms. Some of the recent optimization algorithms used for parameter extraction are the genetic algorithm (GA) [24], differential evolution (DE) [25], simulated annealing (SA) [26], pattern search (PS) [27], harmony search (HS) [28], cuckoo search (CS) [29], flower pollination algorithm [30], bacterial foraging optimization (BFO) [31], bird mating [32], and artificial bee swarm optimization (ABSO) [33]. The proposed algorithms suffer from the problem of premature convergence. The primary disadvantage of GA is that it involves wide parameter optimization search space which makes the system quite complicated and slow. The problem of large search space was overcome by implementing PSO. However, it imposed the problem of the randomly chosen initial parameter value. The value exchange in SA between the cooling timetable and the original temperature makes it less popular. There is a likelihood that PSO will choose an incorrect pattern, leading to premature convergence or no convergence. PSO with reverse barrier restriction for series resistance (Rs), shunt resistance (Rsh), and diode ideality factor (a) is suggested for fast and coherent convergence of optimization issue to global optima, considering the temperature impact to reduce the modeling errors in differential evolution [31-35]. Although the BFO technique offers excellent outcomes but involving too many parameters that have complicated the scheme and imposed a computational strain. Authors in [36], implemented improved teaching-learning based optimization (ITLBO), where a good trade-off is established between the exploration and exploitation by eliminating the worst learner. This increases the global search ability of the population in a defined search space. A hybridization approach is carried out by the researchers in [34] for parameter 
extraction of solar PV cell. In this approach, the hybridization of two algorithms are implemented, the firefly and pattern search. The exploration phase is completed by the firefly algorithm during the first half iteration and then the pattern search algorithm takes control of the population for the exploitation phase. A new opposition-based learning approach is incorporated with whale optimization and shuffled complex evolutionary algorithm for optimization of solar cell parameters [35,36]. This approach is tested on unimodal as well as on multimodal benchmark functions and simulation results clearly show the robustness of the algorithms.

The whale optimization algorithm (WOA) [37] and particle swarm optimization (PSO) [38] are the two most prominent used metaheuristics techniques as available in the literature. However, they differ from each other in the search mechanism for the best solution in a defined search space. WOA mimics the social behaviour of humpback whales while PSO mimics the searching behaviour of the birds in a group. It is shown by many previous research studies that WOA is good at exploring [39] the search space but suffers from a slow convergence rate due to low exploitation ability while PSO don't have good capability in exploring [40] the search space but have good local search capability. the convergence speed of the algorithm. In [41], the author proposed a chaotic WOA (CWOA) to improve maps utilized their dynamic behavior to prevent an optimization algorithm to trap in local optima and improves its global search capability. In [42], the author proposed Levy flight trajectory based WOA (LWOA) to improve the accuracy and convergence speed of the algorithm. Levy flight allowed for the algorithm to get rid of local optima and prevents premature convergence.

There are certain complex and non-convex optimization problems that are not solved by continuous metaheuristic therefore, in [43], the author proposed binary WOA (BWOA). In [44], the author proposed a modified WOA that includes whale memory and new random search agent to enhance the exploitation capability of the algorithm. In [45], the author improved the exploration capability of WOA and proposed three modified WOA which are based on opposition-based learning, exponentially decreasing parameters, and re-initialization of the worst particles. The hybridization of metaheuristic algorithms is another approach to improve the exploration and exploitation capability of population based stochastic algorithm. Furthermore, researchers have proposed hybrid approach grey wolf optimization (HAGWO) [46], WOA-CBO (colliding bodies optimization) [47], memetic-WOA (MWOA) [48], WOA-SA (simulated annealing) [39], WOA-MFO (moth flame optimization) [49], Sine-Cosine (SC-WOA) [50], WOA-PS (Pattern Search) [51], and Brain Storm (BS-WOA) [52-54] to improve the global and local search capability of WOA.

According to the literature survey, WOAPSO has not yet been implemented for the parameter extraction of the solar cell (and it cannot be used to establish a PV parameter estimation technique that can overcome all existing techniques). Therefore, this research paper aims to anticipate a new parameter estimation algorithm for solar cell/module. The novelty of the proposed study is that the exploitation capability of WOA is significantly improved by incorporating the exploitation capability of PSO with adaptive weight in sequential mode. As a result, equivalent circuit parameters converge equally good to the true values with minimum error. The proposed WOAPSO algorithm's performance is measured based on convergence analysis, robustness, reliability, and statistical analysis for three PV models at diverse operating conditions.

The manuscript is organized as follows: the problem formulation and mathematical model for solar PV cell/module are presented in Section 2. Section 3 gives a brief introduction of the WOA, PSO, and proposed WOAPSO algorithm and discussed its implementation to estimate the optimized value of unknown parameters of a single-diode, double-diode, and PV module model. In Section 4, the simulation results of the WOAPSO algorithm are discussed and compared with pre-existing metaheuristic algorithms. Finally, Section 5 provides a conclusive remark to summarize the paper. 


\section{Methodology}

In this section, the equivalent circuits of a photovoltaic solar cell are formulated using a single-diode and double-diode models. These equivalent circuit models are used to describe the current-voltage characteristics of a solar cell.

\subsection{PV Panel Model}

The equivalent circuit of PV panel module is shown in Figure 1. The relation between current and voltage at output terminal for the PV panel module is expressed as:

$$
I_{l} / N_{p}=I_{p}-I_{S D}\left[\exp \left(\frac{q\left(V_{l} / N_{s}+R_{s} I_{l} / N_{p}\right)}{a_{1} k_{B} T}\right)-1\right]-\frac{V_{l} / N_{s}+R_{s} I_{l} / N_{p}}{R_{s h}}
$$

where $N_{s}$ and $N_{p}$ represents the number of solar cells connected in series and parallel respectively. It is clearly depicted from Figure 1 that only five parameters $\left(I_{p}, I_{S D}, a_{1}, R_{s}\right.$ and $R_{s h}$ ) are needed to be estimated for minimum value of the RMSE.

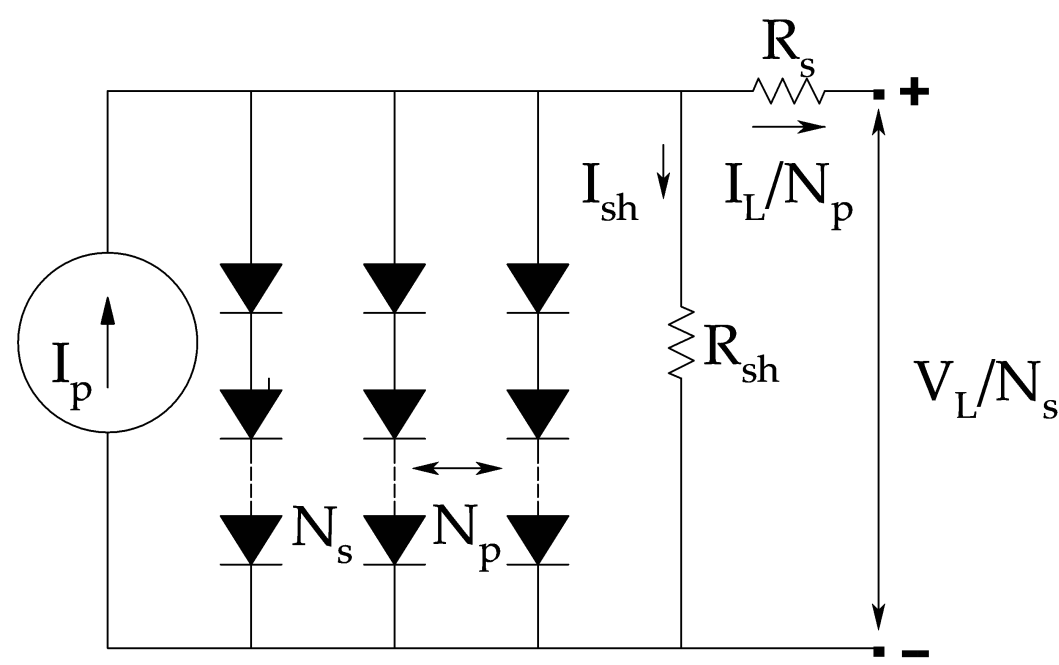

Figure 1. Equivalent circuit of PV panel module model.

\subsection{Objective Function}

The key purpose of this work is to optimize the unknown parameters for both the models (SDM and DDM) and to reduce the error between experimental and estimated data. The objective function for error used here is same as the authors have used previously in as:

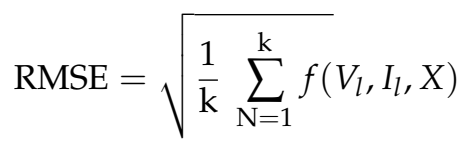

where $V_{l}$ and $I_{l}$ are the measured voltage and current of PV module. The parameter ' $k$ ' stands for the number of experimental data set. The best solution found by WOAPSO is represented by a vector $X$. For the single-diode model:

$$
\left\{\begin{array}{c}
f_{\text {single }}\left(V_{l}, I_{l}, X\right)=I_{p}-I_{S D}\left[\exp \left(\frac{q\left(V_{l}+I_{l} R_{s}\right)}{a_{1} k_{B} T}\right)-1\right]-\frac{V_{l}+I_{l} R_{s}}{R_{s h}}-I_{l} \\
\left(X=I_{p}, I_{S D}, a_{1}, R_{s}, R_{s h}\right)
\end{array}\right.
$$

For the double-diode model:

$$
\left\{\begin{array}{c}
f_{\text {double }}\left(V_{l}, I_{l}, X\right)=I_{p}-I_{S D 1}\left[\exp \left(\frac{q\left(V_{l}+I_{l} R_{s}\right)}{a_{1} k_{B} T}\right)-1\right] \\
-I_{S D 2}\left[\exp \left(\frac{q\left(V_{l}+I_{l} R_{s}\right)}{a_{2} k_{B} T}\right)-1\right]-\frac{V_{l}+I_{l} R_{s}}{R_{s h}}-I_{l} \\
\left(X=I_{p}, I_{S D 1}, I_{S D 2}, a_{1}, a_{2}, R_{S}, R_{s h}\right)
\end{array}\right.
$$


For the PV panel module model:

$$
\left\{\begin{array}{c}
f_{\text {single }}\left(V_{l}, I_{l}, X\right)=I_{p}-I_{S D}\left[\exp \left(\frac{q\left(\frac{V_{l}}{N_{s}}+\frac{R_{s} I_{p}}{N_{p}}\right)}{a_{1} k_{B} T}\right)-1\right] \\
-\frac{V_{l} / N_{s}+R_{s} I_{l} / N_{p}^{L}}{R_{s h}}-I_{l} / N_{p} \\
\left(X=I_{p}, I_{S D}, a_{1}, R_{S}, R_{s h}\right)
\end{array}\right.
$$

\subsection{Hybrid Algorithm}

The hybridization of the metaheuristic algorithm plays a vital role in improving their performance. The fundamental principle of hybridization is to blend the best features of two or more metaheuristic algorithms to improve search capability, accuracy, and convergence speed of an individual algorithm. A hybrid algorithm is also known as a memetic algorithm. In the last few years, researchers have proposed different strategies for hybridizing metaheuristic algorithms. The three most explored methodologies of hybridization are multi-stage, sequential and parallel.

In the multi-stage methodology, one of the algorithms globally explores the search space and the second algorithm locally discovers the optimal solution. In sequential search, both the algorithms run sequentially and find the optimal solution in the search space. In the parallel mode, both the algorithms run parallel on the same population of the defined problem.

\subsubsection{Particle Swarm Optimization (PSO)}

Particle swarm optimization is a nature inspired stochastic optimization technique proposed by J. Kennedy and R. C. Eberhard in 1995. It is a population-based computationally inexpensive technique that is inspired by the social behaviour of fish schooling and bird flocking. The methodology of the algorithm is that the swarm of particles fly in the search space and finds the optimal solution by updating their own best solution and the best solution obtained by the swarms. The swarm is randomly initialized as particles in $\mathrm{N}$-dimensional search space with position $x_{i}$ and velocity $v_{i}$. The position of the particles represents the probable solution, and the velocity represents the rate of change of position of the particle concerning the current position. The particles change their positions with respect to the positions of the best particle. The velocity update equations are given by:

$$
\begin{gathered}
v_{i}^{d}(t+1)=w \times v_{i}^{d}(t)+c_{1} \times r_{1} \times\left(\text { pbest }_{i}^{d}(t)-x_{i}^{d}(t)\right)+c_{2} \times r_{2} \times\left(\text { gbest }^{d}-x_{i}^{d}\right) \\
x_{i}^{d}(t+1)=x_{i}^{d}(t)+v_{i}^{d}(t+1)
\end{gathered}
$$

where $v_{i}^{d}(t)$ and $x_{i}^{d}(t)$ represents the velocity and position of $i$ th particle in $d$ th dimension at $t$ th iteration, $v_{i}^{d}(t+1)$ and $x_{i}^{d}(t+1)$ is the velocity and position of the ith particle in $\mathrm{dth}$ dimension at $(t+1)$ th iteration. pbest $t_{i}^{d}$ represents the current best position of the particles and gbest $t^{d}$ represents the best position among all the particles in $d$ th dimension, $c_{1}$ and $c_{2}$ are the acceleration parameter, $r_{1}$ and $r_{2}$ are the random number in the range $[0,1]$ and $w$ is the inertial weight vector which maintains balance between exploration and exploitation.

\subsubsection{Whale Optimization Algorithm (WOA)}

The whale optimization algorithm is a population-based optimization algorithm that mimics the social behaviour of humpback whales and was proposed by Mirjalili and Lewis in 2016. Humpback whales are long in size and have an interesting food searching capability: they attack their prey (krill and small fishes) by a bubble-net hunting strategy. WOA is inspired by this hunting behaviour, and works in three phases. First, it searches for prey then encircles the prey and lastly, attacks the prey. Humpback whales swim around the prey either following a shrinking path or through a spiral movement. A probability factor $p$ assumed to be $50 \%$ simultaneously choose either of the two movements. 


\section{Shrinking Movement}

Initially in the exploration phase, humpback whales search around a prey chosen randomly in the search space with the following mathematical model:

$$
\begin{gathered}
\vec{D}=\left|\vec{C} \times \vec{X}_{\text {rand }}-\vec{X}\right| \\
\vec{X}(t+1)=\vec{X}_{\text {rand }}-\vec{A} \times \vec{D}
\end{gathered}
$$

where $t$ is the current iteration and $(t+1)$ th is the next iteration, $\vec{X}_{\text {rand }}$ is the random position of the prey, $\vec{A}$ and $\vec{C}$ are the coefficient vectors and is defined as:

$$
\begin{gathered}
\vec{A}=2 \vec{a} \vec{r}-\vec{a} \\
\vec{C}=2 \times \vec{r}
\end{gathered}
$$

where $\vec{a}$ is decreased from 2 to 0 over the course of iterations and $\vec{r}$ is the random number in the range $[0,1]$. In the exploitation phase the position of whales are updated based on the position of the best search prey $\vec{X}^{*}$. Mathematically it is defined as:

$$
\begin{gathered}
\vec{D}=\left|\vec{C} \times \overrightarrow{X^{*}}-\vec{X}\right| \\
\vec{X}(t+1)=\overrightarrow{X^{*}}-\vec{A} \times \vec{D}
\end{gathered}
$$

Spiral Movement

In the spiral movement of the humpback whale, first the distance is evaluated between the whale located at $(X, Y)$ and best search prey located at $\left(X^{*}, Y^{*}\right)$. Once the distance is evaluated then the helix-shaped movement of whale around the prey is defined with following mathematical equation:

$$
\vec{X}(t+1)=\overrightarrow{D^{\prime}} \cdot e^{b l} \cdot \cos (2 \pi l)+\overrightarrow{X^{*}}(t)
$$

where $\overrightarrow{D^{\prime}}=\left|\overrightarrow{X^{*}}(t)-\vec{X}(t)\right|$ is the distance between the whale and best searched prey, $b$ is the constant which maintains the shape of the logarithmic spiral and 1 is the random number defined in the range $[-1,1]$.

In WOA, coefficient vector ' $A$ ' maintains the balance in exploration and exploitation, when the value of $p<0.5$ and $A>1$ then the positions are updated by Equations (9) and (13) while when $p<0.5$ and $A<1$ the positions are updated by Equations (13) and (14) and when the $p \geq 0.5$ then the positions are updated using Equation (14).

\subsubsection{Hybrid WOAPSO Algorithm}

In this section, the principle of the proposed hybrid WOAPSO algorithm is briefly addressed. In general, the performance of any optimization technique while solving any NLP problem is affected by premature convergence and slow rate of convergence. Some algorithms better explore the search space and have a slow convergence rate while some algorithms less diversely explore the search space and did not find the optimal solution. Maintaining the balance between exploration and exploitation is a critical issue in any optimization algorithm. WOA has good exploration capability but exploitation depends on evaluating the distance between the whale and the best position of the prey, and if the distance is large then it takes more time to converge. While PSO has fast rate of convergence but it is prone to premature convergence due to weakness in global search capability. Since in PSO, if the global best solution gets trapped in local optima, then the rest of the particles 
do not explore the search space and follow the global best solution, and become trapped in local optima. Therefore, it can be concluded that WOA is good at exploring the search space, but suffers from a slow convergence rate while PSO doesn't have good capability in exploring the search space but have good local search capability. The aim of the proposed hybrid algorithm is to enhance the exploitation capability of WOA by embedding the PSO algorithm to find an optimal solution around the region explored by WOA. The proposed approach is mixed, co-evolutionary in which PSO is used as a component of WOA and thus the hybrid approach utilizes the strength of both the algorithms to avoid the premature convergence and local optima. Figure 2 depicts the process flow chart of the proposed algorithm. The mathematical model of the proposed algorithm is illustrated in the following steps:

Step 1: Initialize the random population of search agents with position and velocity defined as:

$$
\begin{aligned}
& X_{i}=\left(x_{i}^{1}, \ldots \ldots \ldots \ldots x_{i}^{d}, \ldots \ldots \ldots x_{i}^{n}\right), \text { for } i=1,2, \ldots \ldots \ldots \ldots . . . \\
& V_{i}=\left(v_{i}^{1}, \ldots \ldots \ldots \ldots v_{i}^{d}, \ldots \ldots \ldots v_{i}^{n}\right), \text { for } i=1,2, \ldots \ldots \ldots \ldots . N
\end{aligned}
$$

Step 2: Calculate the fitness of each search agent. If the problem is the minimization problem, then $\vec{X}^{*}$ is the position corresponding to the minimum fitness and for maximization problem $\vec{X}^{*}$ is the position corresponding to the maximum fitness. $\vec{X}^{*}$ is the best search agent.

Step 3: Update the constant parameters A, C, using Equations (10) and (11) and 1 lying between $[-1,1]$ and $p$ is the probability between 0 and 1 .

Step 4: If $p<0.5$ and $|A| \geq 1$, then select the random position of search agent $\left(X^{*}\right)$ in search space and update the position of search agent using Equations (9) and (13).

Else if $p<0.5$ and $|A|<1$, then update the position of search agent using Equations (13) and (14).

Else $p>0.5$, then update the position of search agent using Equation (14).

Step 5: Update the velocity of search agent based on the best position of search agent $\left(X^{*}\right)$ in the search space using the following equation:

$$
v_{i}^{d}(t+1)=w \times v_{i}^{d}(t)+c_{1} \times r_{1} \times\left(X^{*}-x_{i}^{d}(t)\right)
$$

Step 6: Update the position of the particles using Equation (17).

Step 7: Go to step 3 until the termination criteria is met. The algorithm terminates when either maximum number of iterations or minimum error criteria is attained.

Step 8: In the last iteration the returned value of $\vec{X}^{*}$ represents the global minimum and the position corresponding to it represents the solution of the problem.

\subsubsection{Implementation of WOAPSO for Parameter Extraction Single-Diode Model}

Initialize the population of search agents of fifth order dimension in the search space. The fifth order dimension represents the photovoltaic current $\left(I_{p}\right)$, series resistance $\left(R_{s}\right)$, shunt resistance $\left(\mathrm{R}_{\mathrm{sh}}\right)$, diode saturation current $\left(\mathrm{I}_{\mathrm{SD}}\right)$ and diode ideality factor $\left(\mathrm{a}_{1}\right)$. The range of these parameters are [0-1, 0.001-0.5, 0-100, 0.01-0.5, 1-2].

Regulate the fitness of all agents in the search space using Equation (3).

Update the position of the agents at every iteration using WOAPSO. The algorithm is designed to work in the minimization mode thus the location of particles that acquire minimum cost represents the optimized parameters of SDM with minimum RMSE. 


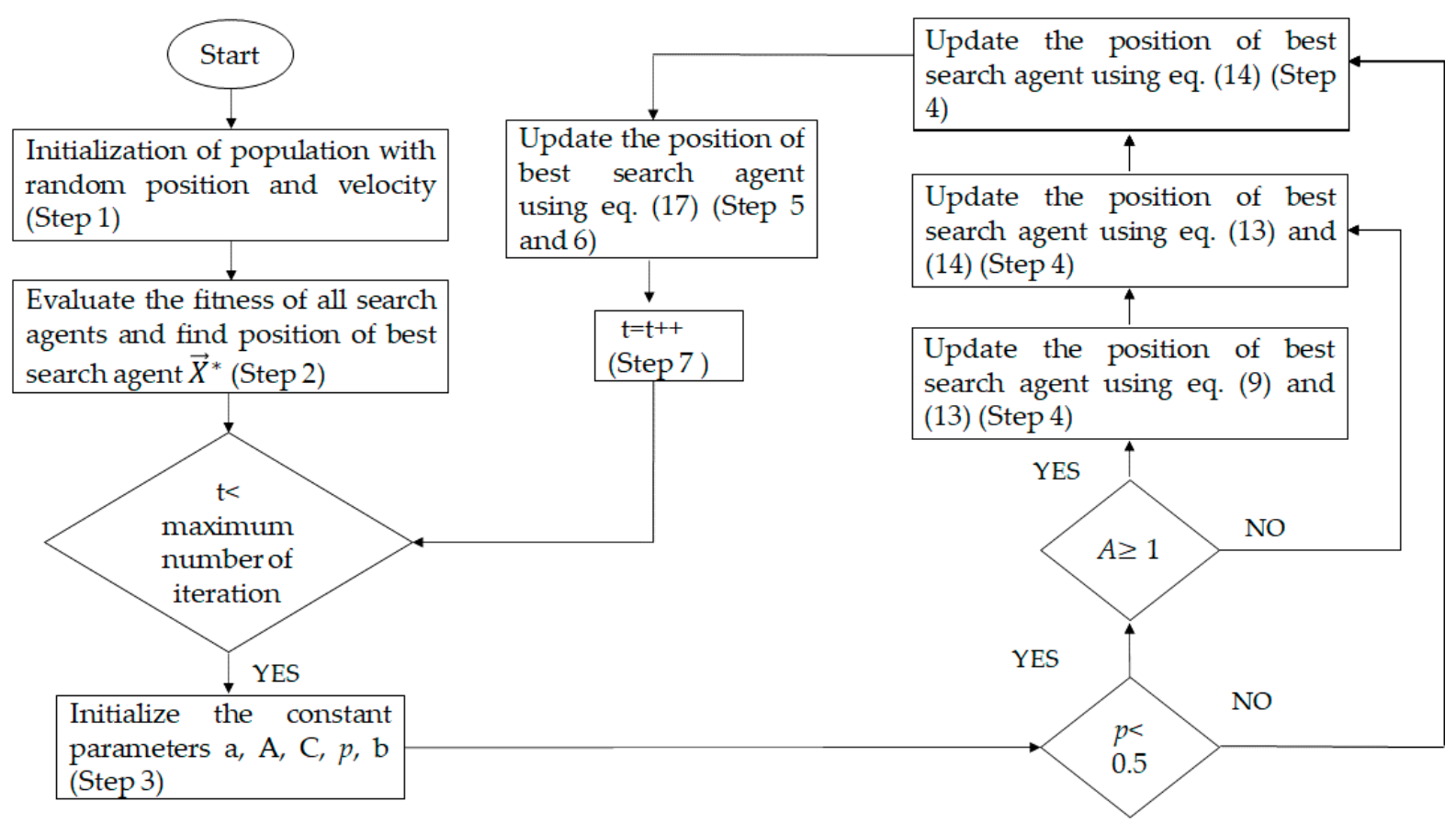

Figure 2. Flowchart of proposed hybrid version of whale optimization and particle swarm optimization WOAPSO algorithm.

\section{Double-Diode Model}

Initialize population of search agents of seventh-order dimension in the search space. The seventh-order dimension represents the photovoltaic current $\left(I_{p}\right)$, series resistance $\left(R_{s}\right)$, shunt resistance $\left(\mathrm{R}_{\mathrm{sh}}\right)$, diode saturation currents $\left(\mathrm{I}_{\mathrm{SD}}, \mathrm{I}_{\mathrm{SD} 1}\right)$, and diode ideality factor $\left(\mathrm{a}_{1}\right.$, $\left.\mathrm{a}_{2}\right)$. The range of these parameters are $[0-1,0.001-0.5,0-100,0.01-0.5,0.01-0.5,1-2,1-2]$.

Regulate the fitness of all agents in the search space using Equation (4).

Update the position of all agents at every iteration using WOAPSO. The algorithm is designed to work in the minimization mode. Thus, the location of particles having minimum cost represents the parameters of the double-diode model with minimum RMSE.

\section{Results}

In this section, the feasibility of the proposed new hybrid WOAPSO was tested and evaluated using mainly two types of PV devices: one PV cell (R.T.C France solar cell) and one PV module (SS2018P) at different solar irradiation. As a result, the retrieved PV cell and module parameters were monitored and used to create simulated I-V data for each device type. The accuracy and reliability of the WOAPSO were assessed by comparing the techniques published in the literature with the existing art. The efficiency of the proposed method is evaluated based on distinct empirical tools such as the individual absolute error (IAE), the relative error (RE), the precision of the curve fitting, and the global minimum convergence patterns. The experimental values of current and voltage are taken from [55] by using R.T.C France solar cell at standard temperature condition i.e., $1000 \mathrm{~W} / \mathrm{m}^{2}$ at $33^{\circ} \mathrm{C}$. The SS2018P PV module is composed of 36 polycrystalline cells connected in series and generate the I-V data under different irradiance levels i.e., $1000 \mathrm{~W} / \mathrm{m}^{2}, 870 \mathrm{~W} / \mathrm{m}^{2}$, $720 \mathrm{~W} / \mathrm{m}^{2}$ and $630 \mathrm{~W} / \mathrm{m}^{2}$. The data collection consists of a total of $20 \mathrm{I}-\mathrm{V}$ measurements for solar cell and 27 for PV module. The values of current and voltage for solar PV module (SS2018P) are measured across variable resistive load (0.1-250 $\Omega, 2 \mathrm{~A})$. The measured value of voltage and current at different irradiance level is presented in supplementary materials. For a reasonable comparison, the search ranges (i.e., upper and lower bound) for each parameter are tabulated in Table 1, which are the same as those being used by investigators 
in [27]. The proposed WOAPSO algorithm is implemented on MATLAB 2018a platform with Intel ${ }^{\circledR}$ core TM i7-HQ CPU, $2.4 \mathrm{GHz}, 16 \mathrm{~GB}$ RAM Laptop. In order to conduct the experiment, the sample size, and the estimated number of objective function evaluations are set at 30 and 50,000, respectively. Furthermore, a minimum of 30 separate runs are carried out to prevent the contingency.

Table 1. Range of parameters for SDM, DDM and PV Module.

\begin{tabular}{ccccc}
\hline \multirow{2}{*}{ Parameter } & \multicolumn{2}{c}{ SDM/DDM } & \multicolumn{2}{c}{ SS2018P PV Module } \\
\cline { 2 - 5 } & Lower Bound & Upper Bound & Lower Bound & Upper Bound \\
\hline $\mathrm{I}_{\mathrm{p}}(\mathrm{A})$ & 0 & 1 & 0 & 10 \\
$\mathrm{I}_{\mathrm{sd}}, \mathrm{I}_{\mathrm{sd} 1}(\mu \mathrm{A})$ & 0.01 & 0.5 & 0 & 50 \\
$\mathrm{R}_{\mathrm{s}}(\Omega)$ & 0.001 & 0.5 & 0.001 & 2 \\
$\mathrm{R}_{\mathrm{sh}}(\Omega)$ & 0 & 100 & 0 & 2000 \\
$\mathrm{a}, \mathrm{a}_{1}, \mathrm{a}_{2}$ & 1 & 2 & 0 & 100 \\
\hline
\end{tabular}

\subsection{Parameter Estimation of Single-Diode Model Using WOAPSO}

Only five parameters $\left(I_{p}, I_{s d}, a, R_{s}, R_{s h}\right)$ are required to be estimated for a single-diode model. Table 2 signifies the values of parameters optimized by WOAPSO and RMSE for the comparison. The WOAPSO algorithm provides the lowest RMSE of $7.1700 \times 10^{-4}$ than others (Table 2 and Table S2). Here RMSE values are acquired as the index for the evaluation of results with previously existing algorithms implemented by the researchers.

Table 2. Comparison of WOAPSO with different parameter estimation methods for SDM.

\begin{tabular}{ccccccc}
\hline Algorithms & $\mathbf{I}_{\mathbf{p h}}(\mathbf{A}) \pm \mathbf{S D}$ & $\mathbf{I}_{\mathbf{s d}}(\boldsymbol{\mu} \mathbf{A}) \pm \mathbf{S D}$ & $\mathbf{R}_{\mathbf{s}}(\boldsymbol{\Omega}) \pm \mathbf{S D}$ & $\mathbf{R}_{\mathbf{s h}}(\boldsymbol{\Omega}) \pm \mathbf{S D}$ & $\mathbf{a} \pm \mathbf{S D}$ & $\mathbf{R M S E}$ \\
\hline GSA & $0.7607 \pm 0.0053$ & $0.05 \pm 0.0265$ & $0.0339 \pm 0.0076$ & $63.7784 \pm 4.304$ & $1.5486 \pm 0.0042$ & $1.2012 \times 10^{-3}$ \\
SCA & $0.7595 \pm 0.0209$ & $0.002 \pm 0.034$ & $0.0519 \pm 0.0229$ & $90.0685 \pm 4.517$ & $1.2641 \pm 0.140$ & $1.9123 \times 10^{-3}$ \\
GWO & $0.7695 \pm 0.0038$ & $1 \pm 0.193$ & $0.0269 \pm 0.0037$ & $47.9136 \pm 16.872$ & $1.6232 \pm 0.0311$ & $9.4095 \times 10^{-4}$ \\
PSO & $0.7383 \pm 0.023$ & $1 \pm 0.023$ & $0.0501 \pm 0.0053$ & $25.1251 \pm 3.213$ & $1.6605 \pm 0.024$ & $1.4320 \times 10^{-3}$ \\
WOA & $0.7573 \pm 0.0019$ & $0.016 \pm 0.0056$ & $0.053 \pm 0.0028$ & $58.5839 \pm 0.354$ & $1.2476 \pm 0.0043$ & $9.9529 \times 10^{-4}$ \\
PSOGSA & $0.7677 \pm 0.0071$ & $0.01 \pm 0.006$ & $0.0522 \pm 0.0066$ & $18.4587 \pm 37.62$ & $1.218 \pm 0.0349$ & $1.2400 \times 10^{-3}$ \\
WOAPSO & $0.7597 \pm 0.0012$ & $0.499 \pm 0.004$ & $0.0342 \pm 0.0007$ & $83.0131 \pm 0.027$ & $1.5483 \pm 0.001$ & $7.1700 \times 10^{-4}$ \\
\hline
\end{tabular}

The characteristics curve of current-voltage and power-voltage for a single-diode model is redrawn based on the best optimized parameters obtained by implementing the WOAPSO algorithm and depicted in Figure 3. It is observed that the calculated data obtained by the WOAPSO is very effectively in keeping with the experimental data set, under S.T.C (i.e., $1000 \mathrm{w} / \mathrm{m}^{2}$ and $33^{\circ} \mathrm{C}$ ), all over the voltage range. The error relating the measurement results for each of 20 pair points is determined by IAE and RE, which is calculated by using Equations (18) and (19), respectively.

$$
\begin{gathered}
I A E=\left|I_{\text {measured }}-I_{\text {simulated }}\right| \\
R E=\left(I_{\text {measured }}-I_{\text {simulated }}\right) / I_{\text {measured }}
\end{gathered}
$$




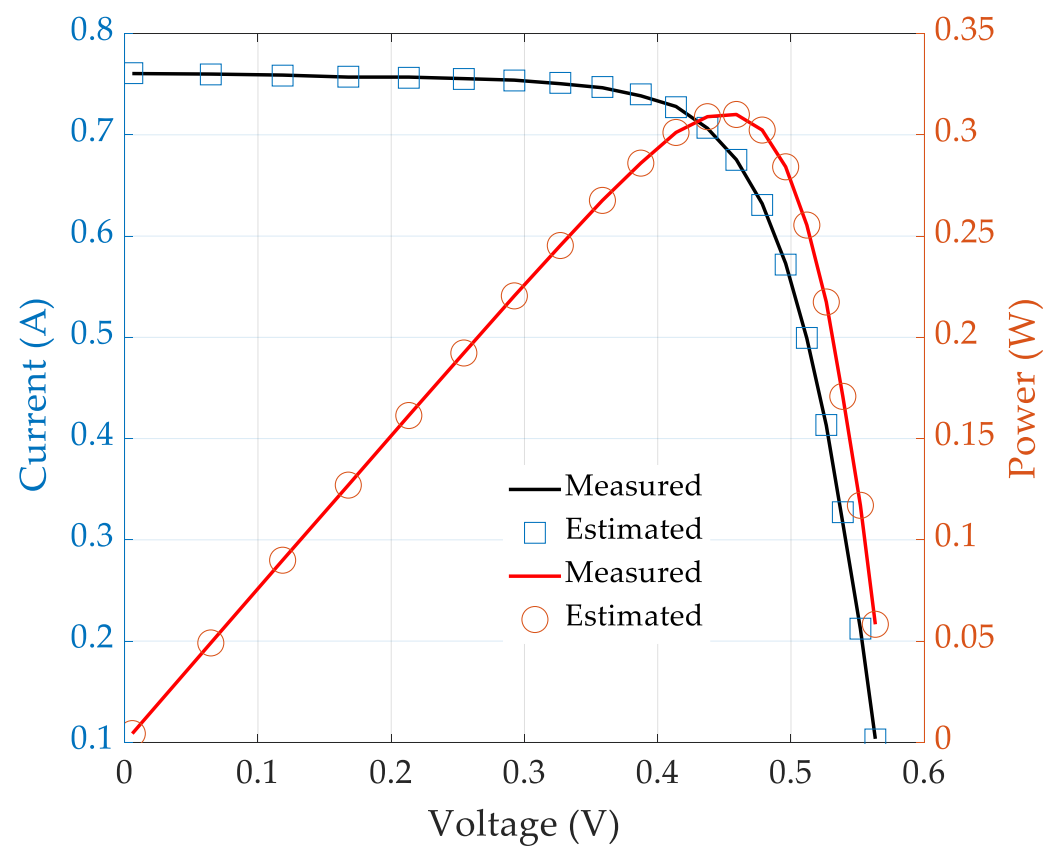

Figure 3. I-V and P-V characteristics curve for estimated and experimental values for single-diode model of R.T.C France solar cell.

\subsection{WOAPSO for Parameter Estimation of Double-Diode Model}

In the case of DDM, the seven parameters $\left(I_{p}, I_{s d}, I_{s d 1}, a_{1}, a_{2}, R_{s}, R_{s h}\right)$ are required to be optimized. The values of optimized parameters and minimum of RMSE are presented in Table 3. The characteristics curve in terms of current-voltage and power-voltage for the double-diode model is redrawn based on the best optimized parameters (Figure 4). It can be observed that the estimated data based on optimized parameters are in keeping with the experimental data set.

Table 3. Comparison of WOAPSO with different parameter estimation methods for DDM.

\begin{tabular}{|c|c|c|c|c|c|c|c|c|}
\hline Algorithms & $\begin{array}{c}\mathbf{I}_{\mathrm{ph}}(\mathrm{A}) \pm \\
\mathrm{SD}\end{array}$ & $\begin{array}{c}I_{s d 1}(\mu A) \pm \\
S D\end{array}$ & $\begin{array}{c}\mathrm{I}_{\mathrm{sd} 2}(\mu \mathrm{A}) \pm \\
\mathrm{SD}\end{array}$ & $\begin{array}{c}\mathbf{R}_{\mathbf{s}}(\Omega) \pm \\
\mathrm{SD}\end{array}$ & $\begin{array}{c}\mathbf{R}_{\mathrm{sh}}(\Omega) \pm \\
\mathrm{SD}\end{array}$ & $\mathrm{a}_{1} \pm \mathrm{SD}$ & $\mathbf{a}_{2} \pm \mathbf{S D}$ & RMSE \\
\hline GSA & $\begin{array}{c}0.7641 \pm \\
0.0079\end{array}$ & $\begin{array}{c}0.05 \pm \\
0.177\end{array}$ & $\begin{array}{c}0.001 \pm \\
0.1191\end{array}$ & $\begin{array}{c}0.0344 \pm \\
0.0091\end{array}$ & $\begin{array}{c}37.780 \pm \\
1.21\end{array}$ & $\begin{array}{c}1.9943 \pm \\
0.1756\end{array}$ & $\begin{array}{c}1.5492 \pm \\
0.1076\end{array}$ & $2.03 \times 10^{-3}$ \\
\hline SCA & $\begin{array}{c}0.7623 \pm \\
0.0097\end{array}$ & $\begin{array}{c}0.0012 \pm \\
0.059\end{array}$ & $\begin{array}{c}0.001 \pm \\
0.046\end{array}$ & $\begin{array}{c}0.0595 \pm \\
0.0067\end{array}$ & $\begin{array}{c}52.4903 \pm \\
24.02\end{array}$ & $2 \pm 0.3030$ & $\begin{array}{c}1.2197 \pm \\
0.2088\end{array}$ & $3.18 \times 10^{-3}$ \\
\hline GWO & $\begin{array}{c}0.7609 \pm \\
0.0026\end{array}$ & $\begin{array}{c}0.3156 \pm \\
0.0052\end{array}$ & $\begin{array}{c}0.0001 \pm \\
0.008\end{array}$ & $\begin{array}{c}0.0323 \pm \\
0.0015\end{array}$ & $\begin{array}{c}65.6799 \pm \\
6.5859\end{array}$ & $\begin{array}{c}1.9426 \pm \\
0.0625\end{array}$ & $\begin{array}{c}1.5312 \pm \\
0.0272\end{array}$ & $1.60 \times 10^{-3}$ \\
\hline PSO & $\begin{array}{c}0.7676 \pm \\
0.0016\end{array}$ & $\begin{array}{c}0.0216 \pm \\
0.027\end{array}$ & $\begin{array}{c}0.0947 \pm \\
0.234\end{array}$ & $\begin{array}{c}0.0335 \pm \\
0.012\end{array}$ & $\begin{array}{c}54.9501 \pm \\
5.4630\end{array}$ & $\begin{array}{c}1.4606 \pm \\
0.203\end{array}$ & $\begin{array}{c}1.8363 \pm \\
0.0137\end{array}$ & $2.90 \times 10^{-3}$ \\
\hline WOA & $\begin{array}{c}0.76354 \pm \\
0.0019\end{array}$ & $\begin{array}{c}0.169 \pm \\
0.0017\end{array}$ & $\begin{array}{c}0.163 \pm \\
0.0011\end{array}$ & $\begin{array}{c}0.0410 \pm \\
0.0022\end{array}$ & $\begin{array}{c}35.7342 \pm \\
0.7539\end{array}$ & $2 \pm 0.034$ & $\begin{array}{c}1.4420 \pm \\
0.0036\end{array}$ & $4.30 \times 10^{-3}$ \\
\hline PSOGSA & $\begin{array}{c}0.7611 \pm \\
0.0041\end{array}$ & $\begin{array}{c}0.432 \pm \\
0.0171\end{array}$ & $\begin{array}{l}0.01 \pm \\
0.0021\end{array}$ & $\begin{array}{c}0.0347 \pm \\
0.0042\end{array}$ & $\begin{array}{l}61.72 \pm \\
18.7135\end{array}$ & $\begin{array}{c}1.9 \pm \\
0.0183\end{array}$ & $\begin{array}{c}1.5489 \pm \\
0.0144\end{array}$ & $1.48 \times 10^{-1}$ \\
\hline WOAPSO & $\begin{array}{c}0.7601 \pm \\
0.0007\end{array}$ & $\begin{array}{c}0.5 \pm \\
0.0020\end{array}$ & $\begin{array}{c}0.5 \pm \\
0.0027\end{array}$ & $\begin{array}{c}0.0311 \pm \\
0.0005\end{array}$ & $\begin{array}{l}100 \pm \\
0.4345\end{array}$ & $\begin{array}{c}1.5755 \pm \\
0.0043\end{array}$ & $\begin{array}{c}1.7314 \pm \\
0.0015\end{array}$ & $\begin{array}{c}9.8412 \times \\
10^{-4}\end{array}$ \\
\hline
\end{tabular}




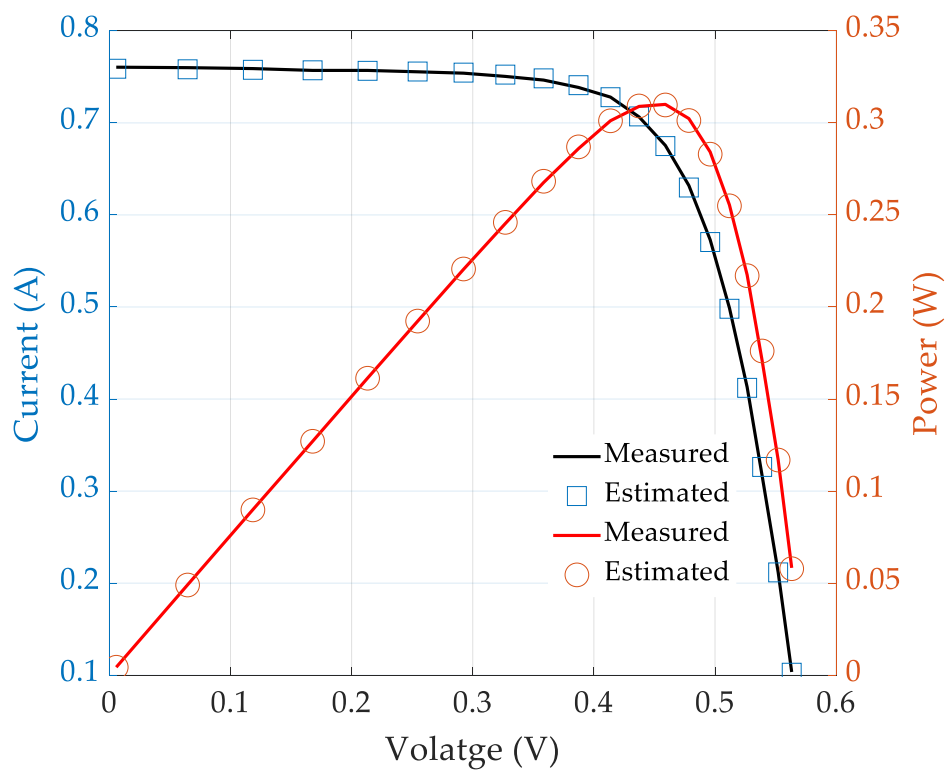

Figure 4. I-V and P-V characteristics curve for estimated and experimental values for double-diode model of R.T.C France solar cell.

\subsection{WOAPSO for Parameter Estimation of SS2018P PV Module}

In order to further evaluate the efficiency of the proposed WOAPSO algorithm, parameters for SS2018P PV module were also estimated at different level of irradiance by utilizing the SDM model. The optimal value of five parameters $\left(I_{p}, I_{s d}, a, R_{s}, R_{s h}\right)$ for SDM of solar PV module at distinct levels of irradiance and constant temperature of $25^{\circ} \mathrm{C}$ is presented in Table 4 and Tables S7-S9. The characteristics curve of current-voltage and power-voltage for solar PV module is redrawn based on best optimized parameters obtained by implementing the WOAPSO algorithm at a different level of irradiance, i.e., $1000 \mathrm{~W} / \mathrm{m}^{2}, 870 \mathrm{~W} / \mathrm{m}^{2}, 720 \mathrm{~W} / \mathrm{m}^{2}$, and $630 \mathrm{~W} / \mathrm{m}^{2}$ and is depicted in Figure 5 . It is found that the calculated data obtained by the WOAPSO is very effectively in keeping with the experimental data set. The curve of IAE between experimental and estimated values at $1000 \mathrm{~W} / \mathrm{m}^{2}, 870 \mathrm{~W} / \mathrm{m}^{2}, 720 \mathrm{~W} / \mathrm{m}^{2}$, and $630 \mathrm{~W} / \mathrm{m}^{2}$, is shown in Figure 6 .

Table 4. Comparison of proposed WOAPSO with different parameter estimation methods for SS2018P PV module $\left(1000 \mathrm{~W} / \mathrm{m}^{2}\right)$.

\begin{tabular}{cccccccc}
\hline \multirow{2}{*}{ Parameters } & \multicolumn{7}{c}{ Algorithms } \\
\cline { 2 - 8 } & GSA & SCA & GWO & PSO & WOA & PSOGSA & WOAPSO \\
\hline $\mathrm{I}_{\mathrm{ph}}(\mathrm{A})$ & $1.0959 \pm 0.0037$ & $1.1742 \pm 0.011$ & $1 \pm 0.024$ & $1.1796 \pm 1.009$ & $1.181 \pm 0.0103$ & $1.168 \pm 0.053$ & $1.1707 \pm 0.0025$ \\
$\mathrm{I}_{\mathrm{sd}}(\mu \mathrm{A})$ & $0.001 \pm 0.2246$ & $0.0092 \pm 0.388$ & $0.001 \pm 0.0759$ & $0.001 \pm 0.707$ & $0.019 \pm 1.034$ & $0.001 \pm 1.358$ & $0.0074 \pm 0.0348$ \\
$\mathrm{R}_{\mathrm{s}}(\Omega)$ & $0.001 \pm 0.0253$ & $0.0011 \pm 0.0187$ & $0.001 \pm 0.0022$ & $0.0022 \pm 0.583$ & $0.0024 \pm 0.007$ & $0.0075 \pm 0.0342$ & $0.2 \pm 0.0017$ \\
$\mathrm{R}_{\mathrm{sh}}(\Omega)$ & $455.5284 \pm 13.67$ & $139.676 \pm$ & $100 \pm 0.842$ & $1308.079 \pm$ & $18.166 \pm 10.71$ & $2000 \pm 4.63$ & $177.219 \pm 0.026$ \\
$\mathrm{a}$ & $53.5976 \pm 0.2493$ & $1.4147 \pm 1.021$ & $1.2628 \pm 0.0399$ & $1.2429 \pm 0.252$ & $1.289 \pm 0.6784$ & $1.246 \pm 0.24$ & $1.3939 \pm 0.0068$ \\
RMSE & $1.68 \times 10^{-1}$ & $1.51 \times 10^{-3}$ & $1.59 \times 10^{-1}$ & $5.13 \times 10^{-3}$ & $7.82 \times 10^{-4}$ & $3.22 \times 10^{-3}$ & $7.6714 \times 10^{-4}$ \\
CPU time $(\mathrm{s})$ & 17 & 12.45 & 9.3 & 10 & 7.56 & 13.17 & 7.81 \\
\hline
\end{tabular}




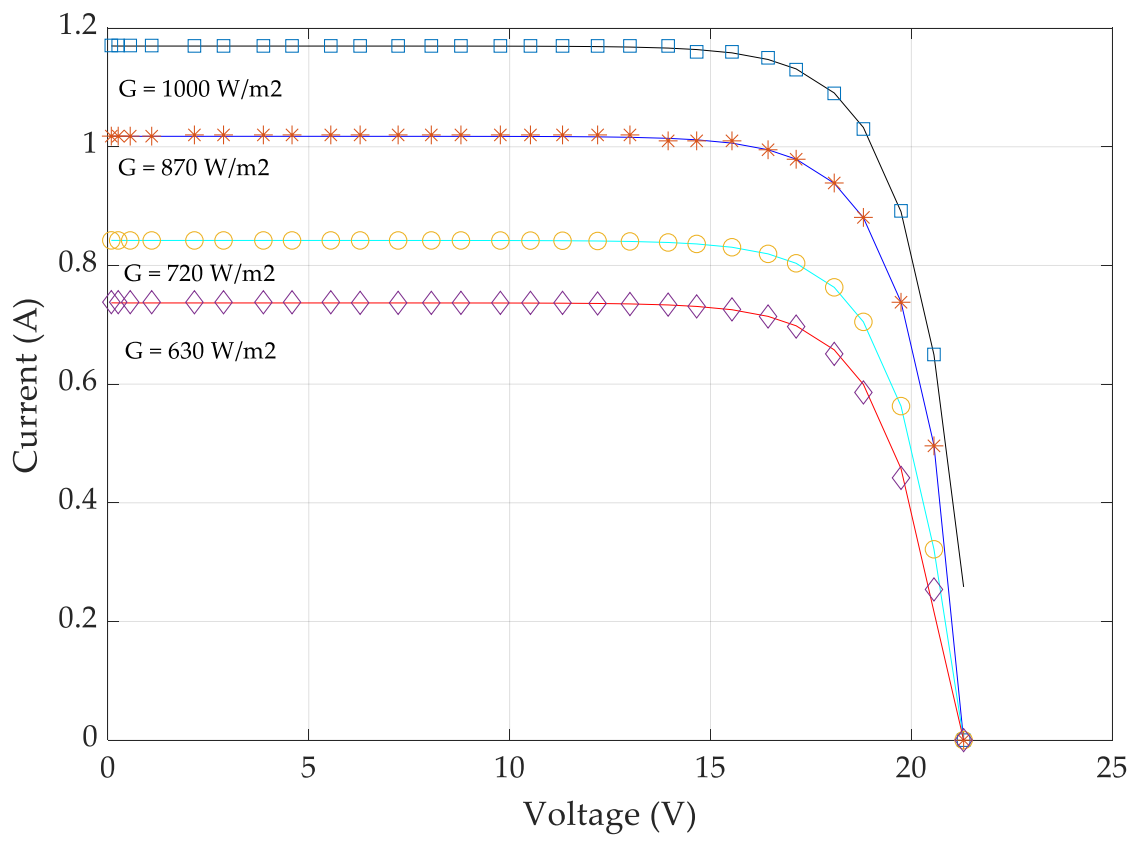

(a)

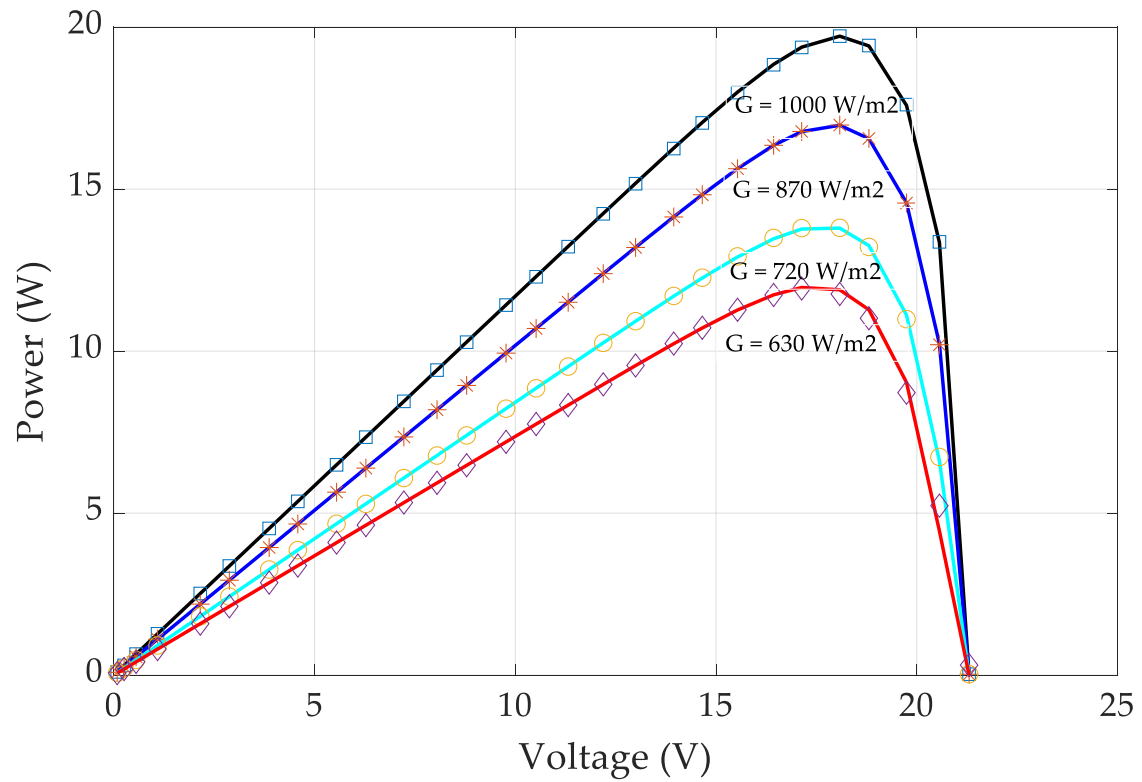

(b)

Figure 5. Characteristics curve of simulated and experimental values at different level of irradiance (a) I-V curve and (b) P-V curve for single-diode model of SS2018P PV module. Symbols represent the estimated data while the solid lines represent the measured data. 


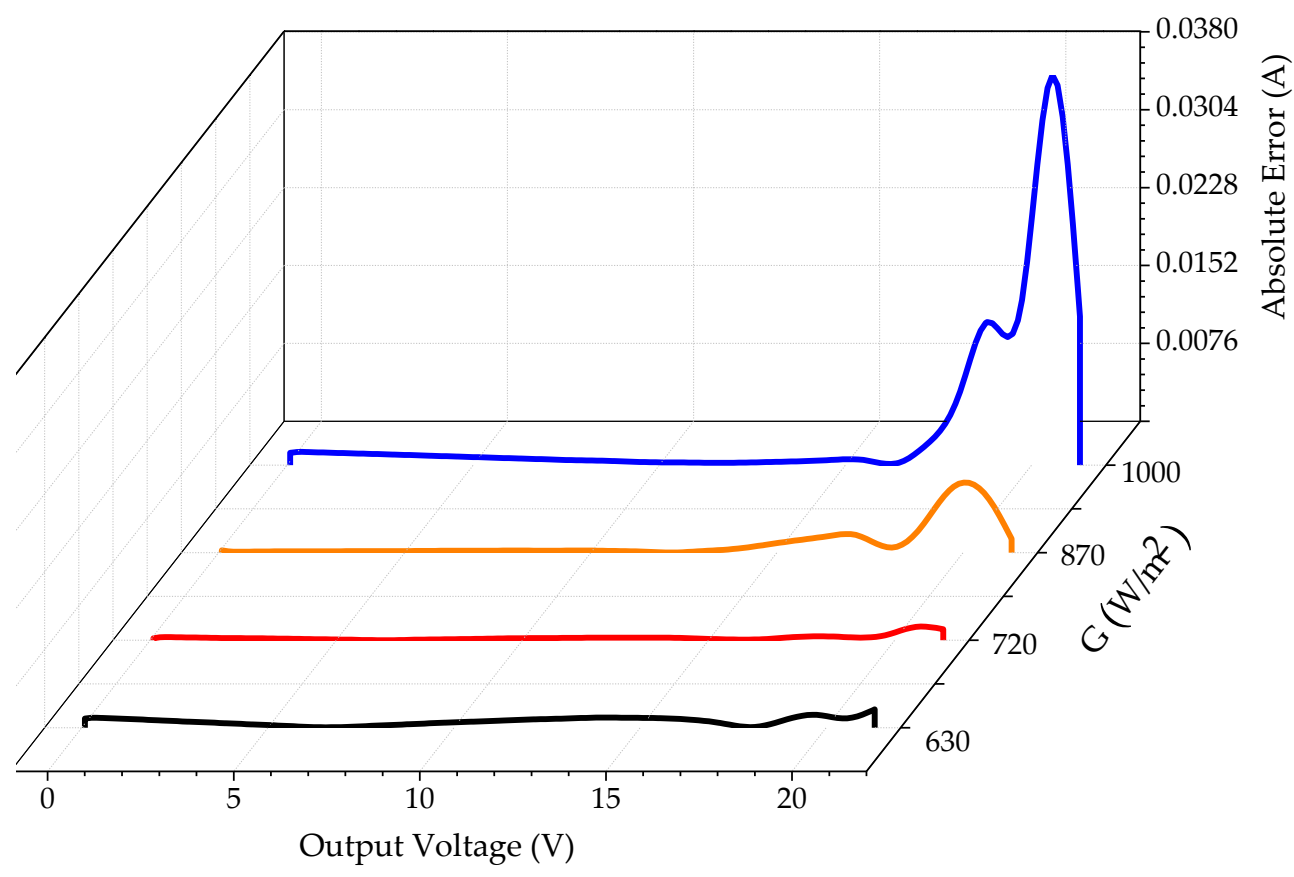

Figure 6. Internal absolute error between measured and simulated current for single-diode model of SS2018P PV module at different level of irradiance.

\subsection{Convergence Analysis}

To analyze the computational competence of WOAPSO, the convergence curves of the single-diode model, double-diode model, and PV module is presented in Figure 7. It is depicted that the proposed WOAPSO algorithm outperforms the GSA, SCA, GWO, PSO, WOA, PSOGSA algorithms in terms of convergence speed and generates a precise solution for the identical number of function evaluations (i.e., 50,000).

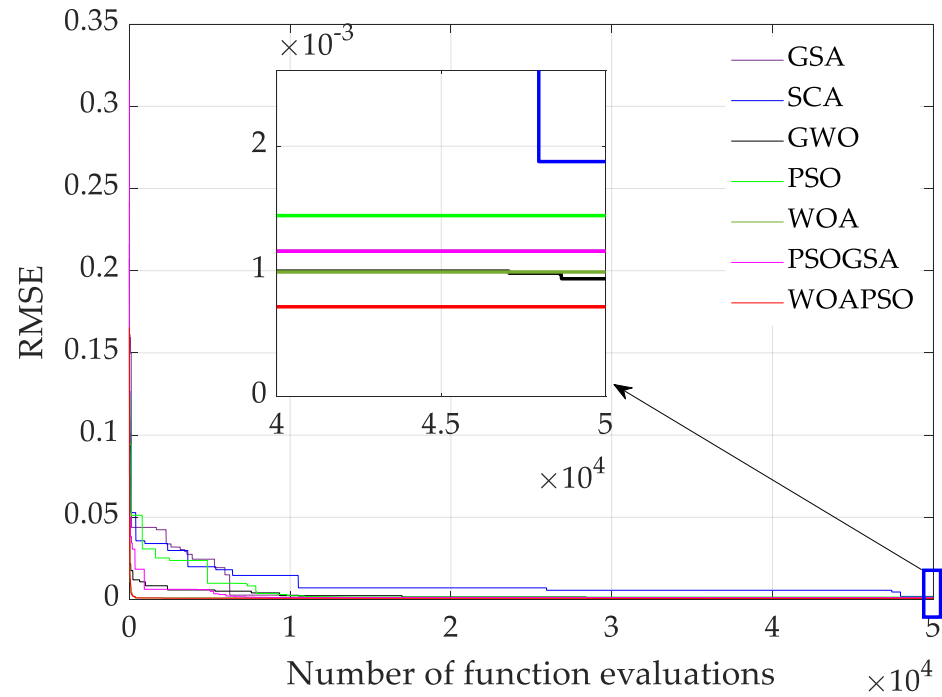

(a)

Figure 7. Cont. 


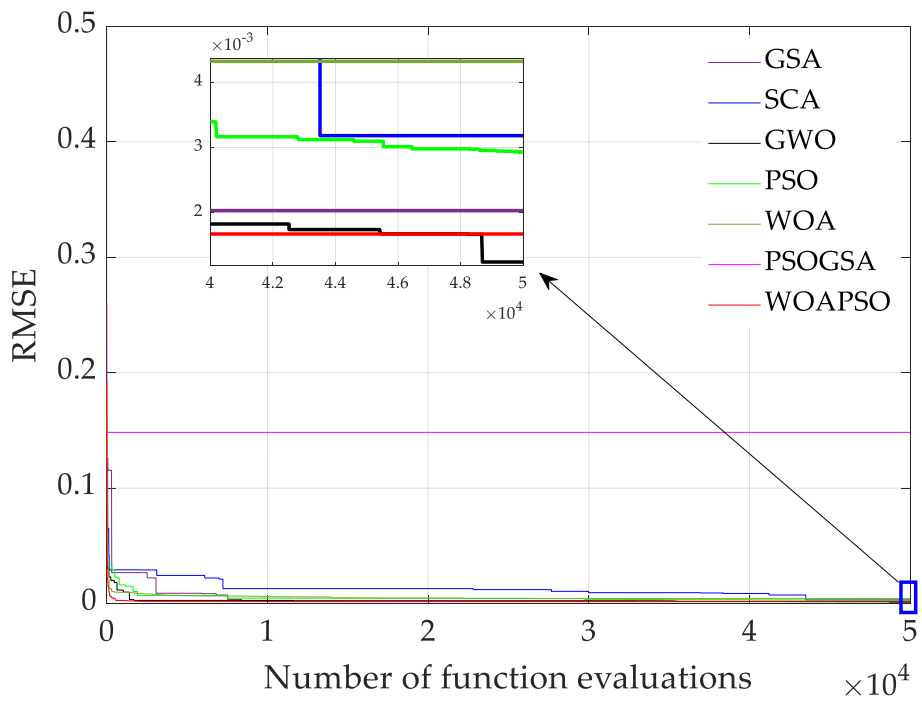

(b)

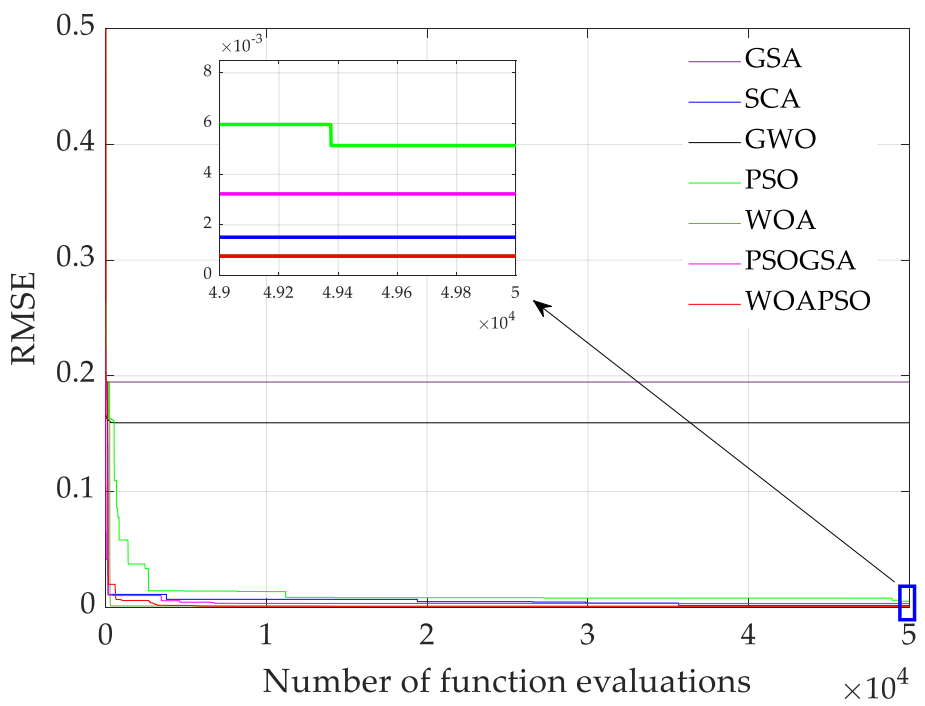

(c)

Figure 7. Convergence curve of WOAPSO and other six algorithms for (a) single-diode model (b) double-diode model of R.T.C France solar cell and (c) single-diode model of SS2018P PV module.

\subsection{Robustness and Statistical Analysis}

This section presents statistical evaluation based on mean, minimum, maximum, and standard deviation of RMSE for all previously implemented methods, and a comparison with respect to precision and consistency of the distinct algorithms in a total of thirty runs and depicted in Table 5. The mean of RMSE is calculated to evaluate the precision of algorithms, and the standard deviation is calculated to evaluate the consistency of the parameter estimation methods. 
Table 5. Statistical results of RMSE of different algorithms for all three models.

\begin{tabular}{cccccc}
\hline \multirow{2}{*}{ Model } & Algorithm & \multicolumn{4}{c}{ RMSE } \\
\cline { 3 - 6 } & & Min & Mean & Max & SD \\
\cline { 3 - 5 } Single-diode & GSA & $1.2012 \times 10^{-3}$ & $5.4701 \times 10^{-3}$ & $2.4211 \times 10^{-1}$ & $1.3129 \times 10^{-3}$ \\
model & SCA & $1.9123 \times 10^{-3}$ & $9.6515 \times 10^{-3}$ & $2.1642 \times 10^{-1}$ & $9.4066 \times 10^{-3}$ \\
& GWO & $9.4095 \times 10^{-4}$ & $1.0441 \times 10^{-3}$ & $1.3506 \times 10^{-3}$ & $1.4050 \times 10^{-5}$ \\
& PSO & $1.4320 \times 10^{-3}$ & $1.2534 \times 10^{-3}$ & $1.4074 \times 10^{-3}$ & $1.1520 \times 10^{-4}$ \\
& WOA & $9.9529 \times 10^{-4}$ & $9.2032 \times 10^{-4}$ & $7.1240 \times 10^{-3}$ & $9.0250 \times 10^{-3}$ \\
& PSOGSA & $1.2400 \times 10^{-3}$ & $1.7660 \times 10^{-3}$ & $5.2460 \times 10^{-3}$ & $1.9880 \times 10^{-3}$ \\
& WOAPSO & $7.1701 \times 10^{-4}$ & $7.8030 \times 10^{-4}$ & $1.3436 \times 10^{-3}$ & $2.4290 \times 10^{-6}$ \\
\hline Double- & GSA & $2.0330 \times 10^{-3}$ & $4.7041 \times 10^{-3}$ & $2.6058 \times 10^{-1}$ & $1.5796 \times 10^{-3}$ \\
diode & SCA & $3.1800 \times 10^{-3}$ & $1.7932 \times 10^{-3}$ & $1.2470 \times 10^{-1}$ & $7.7256 \times 10^{-2}$ \\
model & GWO & $1.6000 \times 10^{-3}$ & $2.6901 \times 10^{-3}$ & $8.2830 \times 10^{-2}$ & $2.6995 \times 10^{-3}$ \\
& PSO & $2.9000 \times 10^{-3}$ & $4.9713 \times 10^{-3}$ & $3.3402 \times 10^{-2}$ & $3.5833 \times 10^{-2}$ \\
& WOA & $4.3000 \times 10^{-3}$ & $5.2967 \times 10^{-3}$ & $1.8698 \times 10^{-2}$ & $3.9481 \times 10^{-3}$ \\
& PSOGSA & $1.4812 \times 10^{-1}$ & $1.4833 \times 10^{-1}$ & $1.4732 \times 10^{-1}$ & $1.0977 \times 10^{-2}$ \\
& WOAPSO & $9.8412 \times 10^{-4}$ & $1.2481 \times 10^{-3}$ & $1.9312 \times 10^{-3}$ & $1.0581 \times 10^{-3}$ \\
\hline SS2018P & GSA & $1.6877 \times 10^{-1}$ & $1.9462 \times 10^{-1}$ & $2.0011 \times 10^{-1}$ & $4.4500 \times 10^{-3}$ \\
module & SCA & $1.5149 \times 10^{-3}$ & $5.2657 \times 10^{-3}$ & $2.0345 \times 10^{-1}$ & $1.0058 \times 10^{-2}$ \\
model & GWO & $1.5938 \times 10^{-1}$ & $1.5940 \times 10^{-1}$ & $5.2494 \times 10^{-1}$ & $1.6793 \times 10^{-2}$ \\
& PSO & $5.1329 \times 10^{-2}$ & $1.2512 \times 10^{-2}$ & $2.6323 \times 10^{-1}$ & $1.9334 \times 10^{-2}$ \\
& WOA & $7.8164 \times 10^{-4}$ & $1.8268 \times 10^{-3}$ & $2.1078 \times 10^{-2}$ & $1.3639 \times 10^{-3}$ \\
& PSOGSA & $3.2258 \times 10^{-3}$ & $3.9510 \times 10^{-3}$ & $2.2333 \times 10^{-1}$ & $4.0336 \times 10^{-3}$ \\
& WOAPSO & $7.6714 \times 10^{-4}$ & $7.4601 \times 10^{-4}$ & $7.5388 \times 10^{-4}$ & $7.4516 \times 10^{-5}$ \\
\hline & & & & &
\end{tabular}

The statistical results presented in Table 5 indicate that WOAPSO is the most accurate and reliable parameter optimization technique. As shown in Table 6, based on the Friedman ranking test result, the best ranking is obtained by the WOAPSO, followed by WOA, GWO, GSA, PSOGSA, SCA, and PSO. Also, Figure 8 shows the distribution of results (i.e., RMSE) obtained from the distinct algorithms in 30 runs in the form of a boxplot graph for the SDM, DDM, and PV module. It can be anticipated from Figure 8 that the proposed WOAPSO algorithm delivers the best results in terms of accuracy and reliability compared to the other six algorithms.

Table 6. Ranking of the proposed WOAPSO and other compared algorithms on three PV models according to the Friedman test.

\begin{tabular}{ccc}
\hline Algorithms & Friedman Ranking & Final Ranking \\
\hline GSA & 3.9 & 4 \\
SCA & 5.91 & 6 \\
GWO & 3.36 & 3 \\
PSO & 6.53 & 7 \\
WOA & 2.05 & 2 \\
PSOGSA & 5.22 & 5 \\
WOAPSO & 1 & 1 \\
\hline
\end{tabular}




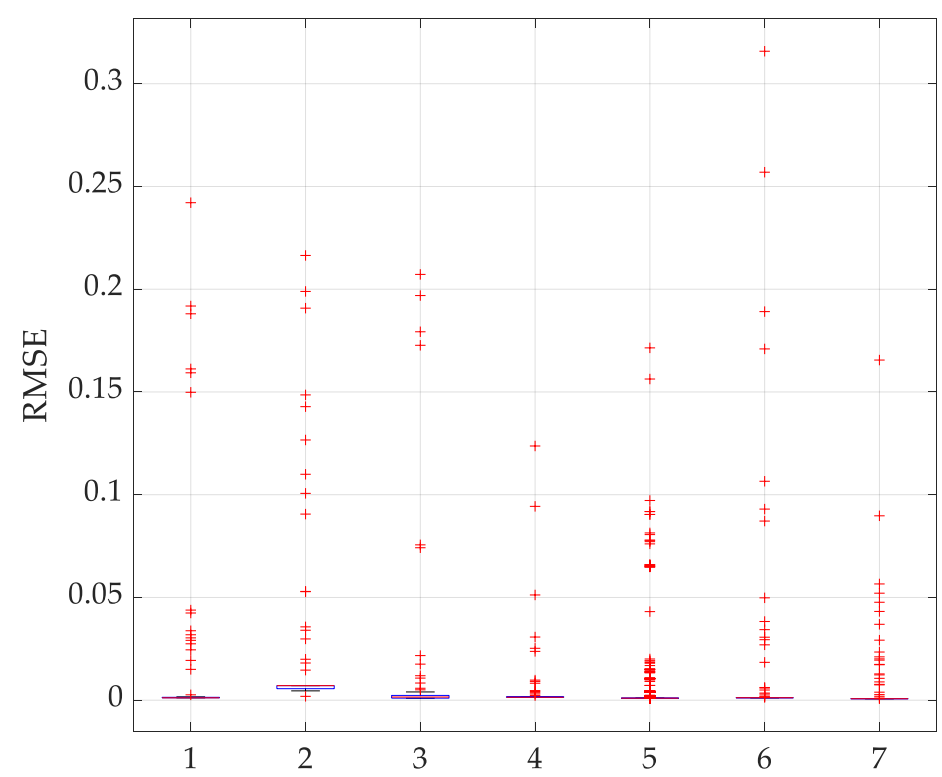

1-GSA, 2-SCA, 3-GWO, 4-PSO, 5-WOA, 6-PSOGSA, 7-WOAPSO

(a)

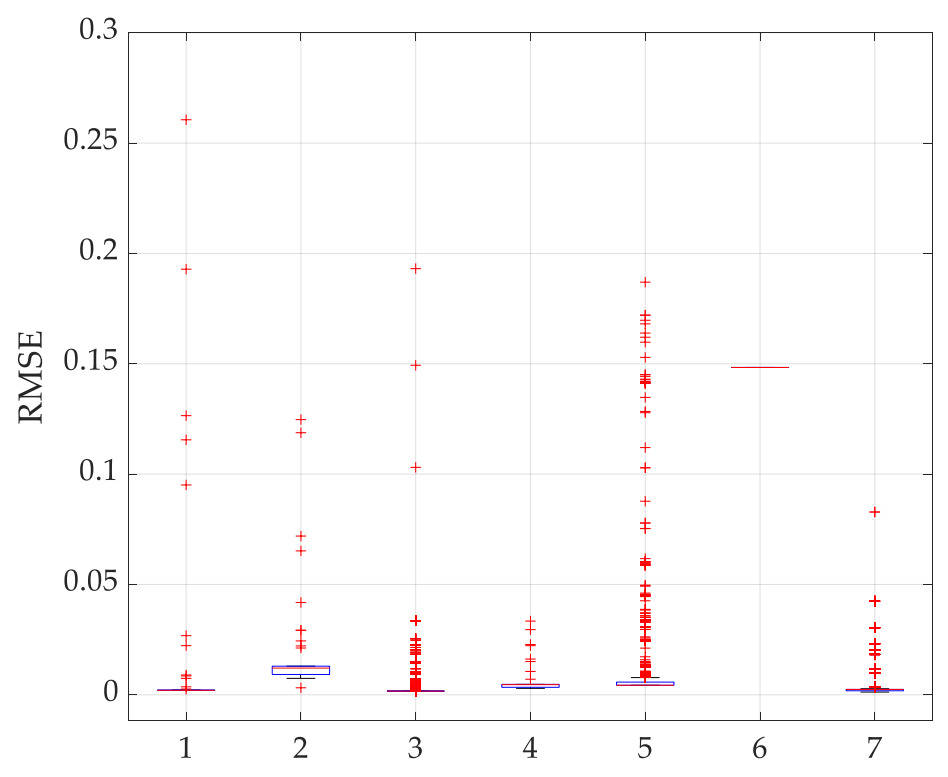

1-GSA, 2-SCA, 3-GWO, 4-PSO, 5-WOA, 6-PSOGSA, 7-WOAPSO

(b)

Figure 8. Cont. 


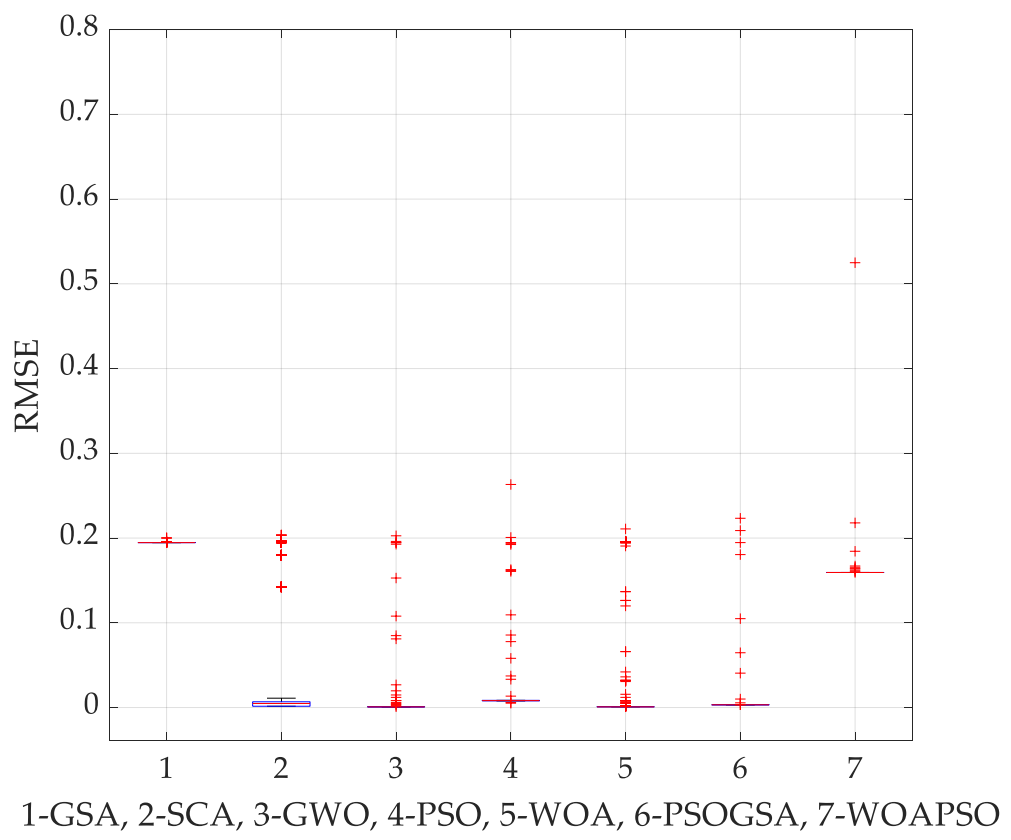

(c)

Figure 8. Boxplot graph of best RMSE in 30 runs for (a) single diose model (b) double-diode model (c) polycrystalline SS2018P PV module.

\section{Discussion}

To evaluate the reliability of the WOAPSO, the proposed hybrid algorithm is compared with six well established metaheuristics algorithms, i.e., GSA [56], SCA [57], GWO [58], PSO [59], WOA [37], PSOGSA [60] as well as other algorithms existing in the literature. It is observed that the estimated parameters based on the optimization process are highly consistent with the experimental data for SDM, DDM, and SS2018P PV module.

For SDM, the hybrid WOAPSO algorithm generates the lowest RMSE values $\left(7.1700 \times 10^{-4}\right)$ compared to the GSA, SCA, GWO, PSO, and WOA, PSOGSA algorithms (Table 2). The RMSE of the proposed WOAPSO algorithm is also compared with previously studied algorithms (Table S2). It is noted that the hybrid WOAPSO algorithm provides the lowest RMSE values than that of others. Table S3 represents the absolute IAE for SDM analysis. The magnitude of IAE for different observations is less than 0.0018 (Table S3), which indicates that the parameters optimized by the WOAPSO are very precise.

In the case of DDM analysis, the MLBSA, EHHO, IJAYA, and GOTLBO algorithms produce the best value of RMSE (Table S4). However, WOAPSO generates the third-best value of RMSE $\left(9.8412 \times 10^{-4}\right)$, which is very close to MLBSA $\left(9.8249 \times 10^{-4}\right)$, EHHO $\left(9.8360 \times 10^{-4}\right)$, IJAYA $\left(9.8293 \times 10^{-4}\right)$, and GOTLBO $\left(9.8317 \times 10^{-4}\right)$. However, the computational cost in terms of function evaluation is 1/3 of MLBSA, EHHO, IJAYA, and GOTLBO. Moreover, WOAPSO shows superiority over other algorithms in terms of RMSE (Table 3). For DDM, the magnitude of IAE for different observations is depicted in Table S5. It is noticed that the IAE values are less than 0.0097, which demonstrates the accuracy of optimized parameters produced by WOAPSO.

For the SS2018P PV module, the hybrid WOAPSO algorithm produces the lowest RMSE values compared to the GSA, SCA, GWO, PSO, WOA, and PSOGSA algorithms. The IAE magnitudes for different observations (at $1000 \mathrm{~W} / \mathrm{m}^{2}$ ) are less than 0.0018 (Table S6). More importantly, the computational time for WOAPSO is less than other algorithms (Table 4). The average execution time of each algorithm on the three PV models is calculated and illustrated in Figure 9. The WOAPSO algorithm requires less time (about $26.1 \mathrm{~s}$ ) 
than GWO, PSO, SCA, WOA, and PSOGSA, while GSA has the worst execution time of approximately $52 \mathrm{~s}$.

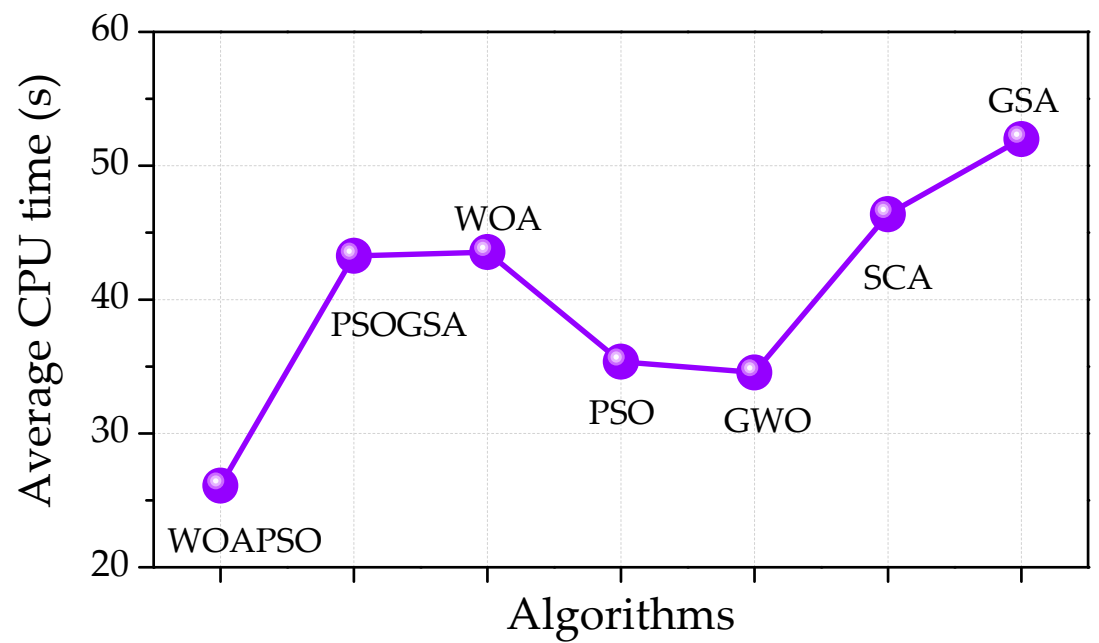

Figure 9. Comparison of the execution time.

Furthermore, the Friedman ranking test is also performed for all algorithms and depicted in Table 6 . Table 6 shows that the proposed WOAPSO algorithm significantly outperforms the GSA, SCA, GWO, PSO, WOA, PSOGSA algorithms for all three models, i.e., single-diode, double-diode, and PV module models.

\section{Conclusions}

In this study, the hybridization of whale optimization and particle swarm optimization algorithm (WOAPSO) is anticipated. The exploitation ability of PSO is only implemented in pipeline mode when WOA stops to improve the best-found solution. The collaboration of both metaheuristic algorithms can establish an effective balance between exploitation and exploration ability. The proposed technique is further used to estimate the parameter of three PV cell models, i.e., single-diode, double-diode, and SS108P PV panel module model at different operating conditions. It should be noted that this suggested technique is, for the first time, intended to track the estimation of parameters for photovoltaic models reliably. The major conclusions are classified as follows:

- The proposed WOAPSO is relatively accurate and reliable at delivering the solution in terms of RMSE as compared with other algorithms such as GSA, SCA, GWO, PSO, WOA, PSOGSA, and existing algorithms in the literature.

- The I-V and P-V characteristic curves and IAE results indicate that WOAPSO can generate the optimized value of estimated parameters for all the models of solar PV cell as compared with other algorithms.

- The statistical analysis clearly depicts the robustness of the proposed WOAPSO technique on parameter estimation problem at different operating conditions.

- The convergence curves demonstrate that the best values of estimated parameters are obtained by WOAPSO, and RMSE is $7.1700 \times 10^{-4}$ and $9.8412 \times 10^{-4}$ in the case of single- and double-diode respectively.

- At different irradiation levels (i.e., $1000 \mathrm{~W} / \mathrm{m}^{2}, 870 \mathrm{~W} / \mathrm{m}^{2}, 720 \mathrm{~W} / \mathrm{m}^{2}$, and $630 \mathrm{~W} / \mathrm{m}^{2}$ ), the proposed WOAPSO algorithm is best in producing optimized parameters $\left(\mathrm{I}_{\mathrm{p}}, \mathrm{I}_{\mathrm{sd}}, \mathrm{a}\right.$, $R_{s}, R_{s h}$ ) and minimum value of RMSE for PV module even at a low level of irradiation $\left(630 \mathrm{~W} / \mathrm{m}^{2}\right)$.

The proposed WOAPSO algorithm has limitation for DDM analysis. The RMSE value $\left(9.8412 \times 10^{-4}\right)$ of WOAPSO algorithm is lower than that of recently developed metaheuristics algorithms (MLBSA, EHHO, IJAYA, and GOTLBO algorithms). 
The WOAPSO is an efficient and robust technique to estimate the unknown optimized parameters of the solar PV model at different operating conditions. For future study, the implementation of proposed WOAPSO to solve the other problems related to energy optimization such as economic load dispatch, energy scheduling and optimization of PV array configuration may also be interesting for scientists and research scholars.

Supplementary Materials: The supplementary materials are available online at https://www.mdpi. com/2079-9292/10/3/312/s1.

Author Contributions: Conceptualization: A.S. (Abhishek Sharma), and A.S. (Abhinav Sharma); methodology and formal analysis: A.S. (Abhishek Sharma) and M.A.; investigation, A.S. (Abhinav Sharma); writing—original draft preparation, A.S. (Abhishek Sharma); writing—review and editing, A.S. (Abhinav Sharma), M.A. and V.J.; supervision, M.A. and B.A.; fund acquisition: B.A. All authors have read and agreed to the published version of the manuscript.

Funding: This work was supported in part by the European Commission H2020 TWINNING JUMP2Excel (Joint Universal activities for Mediterranean PV integration Excellence) project under grant 810809.

Acknowledgments: Authors are thankful to anonymous reviewers and editor for their suggestions.

Conflicts of Interest: The authors declare no conflict of interest.

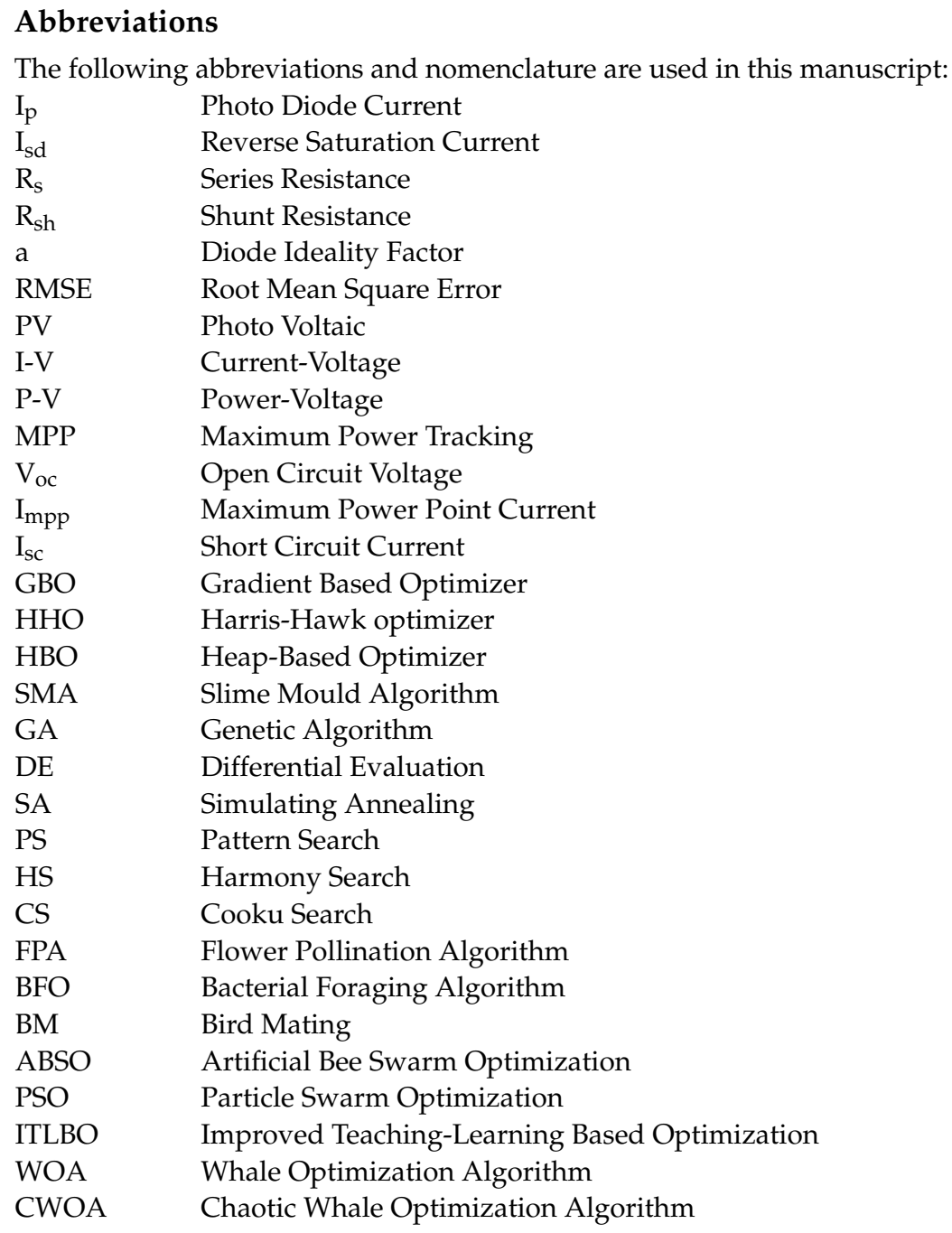




$\begin{array}{ll}\text { LWOA } & \text { Levy flight trajectory based WOA } \\ \text { BWOA } & \text { Binary Whale Optimization Algorithm } \\ \text { HAGWO } & \text { Hybrid Approach Grey Wolf Optimization } \\ \text { WOA-CBO } & \text { Whale Optimization Algorithm Colliding Bodies Optimization } \\ \text { MWOA } & \text { Memetic Whale Optimization Algorithm } \\ \text { WOA-SA } & \text { Whale Optimization Algorithm-Simulated Annealing } \\ \text { WOA-MFO } & \text { Whale Optimization Algorithm-Moth Flame Optimization } \\ \text { SC-WOA } & \text { Sine-Cosine Whale Optimization Algorithm } \\ \text { WOA-PS } & \text { Whale Optimization Algorithm- Pattern Search } \\ \text { BS-WOA } & \text { Brainstorm- Whale Optimization Algorithm } \\ \text { SDM } & \text { Single-diode Model } \\ \text { DDM } & \text { Double-diode Model } \\ \text { IAE } & \text { Internal Absolute Error } \\ \text { RE } & \text { Relative Error } \\ \text { GSA } & \text { Gravitational Search Algorithm } \\ \text { SCA } & \text { Sine Cosine Algorithm } \\ \text { GWO } & \text { Grey Wolf Optimization } \\ \text { PSOGSA } & \text { Particle Swarm Optimization Gravitational Search Algorithm } \\ \text { MLBSA } & \text { Multiple Learning Backtracking Search Algorithm } \\ \text { EHHO } & \text { Enriched Harris Hawks Optimization } \\ \text { IJAYA } & \text { Improved Jaya Algorithm } \\ \text { GOTLBO } & \text { Generalized Opposition-Based Teaching Learning Based Optimization }\end{array}$

\section{References}

1. Panwar, N.L.; Kaushik, S.C.; Kothari, S. Role of renewable energy sources in environmental protection: A review. Renew. Sustain. Energy Rev. 2011, 15, 1513-1524. [CrossRef]

2. Gielen, D.; Boshell, F.; Saygin, D.; Bazilian, M.D.; Wagner, N.; Gorini, R. The role of renewable energy in the global energy transformation. Energy Strategy Rev. 2019, 24, 38-50. [CrossRef]

3. Rajput, S.; Averbukh, M.; Yahalom, A.; Minav, T. An Approval of MPPT Based on PV Cell's Simplified Equivalent Circuit During Fast-Shading Conditions. Electronics 2019, 8, 1060. [CrossRef]

4. Jordehi, A.R. Parameter estimation of solar photovoltaic (PV) cells: A review. Renew. Sustain. Energy Rev. 2016, 61, 354-371. [CrossRef]

5. Aryanpur, V.; Atabaki, M.S.; Marzband, M.; Siano, P.; Ghayoumi, K. An overview of energy planning in Iran and transition pathways towards sustainable electricity supply sector. Renew. Sustain. Energy Rev. 2019, 112, 58-74. [CrossRef]

6. Armghan, H.; Ahmad, I.; Armghan, A.; Khan, S.; Arsalan, M. Backstepping based nonlinear control for maximum power point tracking in photovoltaic system. Sol. Energy 2018, 159, 134-141.

7. Ram, J.P.; Manghani, H.; Pillai, D.S.; Babu, T.S.; Miyatake, M.; Rajasekar, N. Analysis on solar PV emulators: A review. Renew. Sustain. Energy Rev. 2018, 81, 149-160. [CrossRef]

8. Youssef, A.; El-Telbany, M.; Zekry, A. The role of artificial intelligence in photovoltaic systems design and control: A review. Renew. Sustain. Energy Rev. 2017, 78, 72-79. [CrossRef]

9. Gomes, R.C.M.; Vitorino, M.A.; de Rossiter Corrêa, M.B.; Fernandes, D.A.; Wang, R. Shuffled complex evolution on photovoltaic parameter extraction: A comparative analysis. IEEE Trans. Sustain. Energy 2016, 8, 805-815. [CrossRef]

10. Chin, V.J.; Salam, Z.; Ishaque, K. Cell modelling and model parameters estimation techniques for photovoltaic simulator application: A review. Appl. Energy 2015, 154, 500-519. [CrossRef]

11. Brano, V.L.; Ciulla, G. An efficient analytical approach for obtaining a five parameters model of photovoltaic modules using only reference data. Appl. Energy 2013, 111, 894-903. [CrossRef]

12. Louzazni, M. An analytical mathematical modeling to extract the parameters of solar cell from implicit equation to explicit form. Appl. Sol. Energy 2015, 51, 165-171. [CrossRef]

13. Batzelis, E.I.; Papathanassiou, S.A. A method for the analytical extraction of the single-diode PV model parameters. IEEE Trans Sustain. Energy 2015, 7, 504-512. [CrossRef]

14. Khan, F.; Baek, S.H.; Kim, J.H. Wide range temperature dependence of analytical photovoltaic cell parameters for silicon solar cells under high illumination conditions. Appl. Energy 2016, 183, 715-724. [CrossRef]

15. Tao, Y.; Bai, J.; Pachauri, R.K.; Sharma, A. Parameter extraction of photovoltaic modules using a heuristic iterative algorithm. Energy Convers. Manag. 2020, 224, 113386. [CrossRef]

16. Gao, X.; Cui, Y.; Hu, J.; Xu, G.; Yu, Y. Lambert W-function based exact representation for double diode model of solar cells: Comparison on fitness and parameter extraction. Energy Convers. Manag. 2016, 127, 443-460. [CrossRef]

17. Villalva, M.G.; Gazoli, J.R.; Ruppert Filho, E. Comprehensive approach to modeling and simulation of photovoltaic arrays. IEEE Trans. Power Electron. 2009, 24, 1198-1208. [CrossRef] 
18. Chegaar, M.; Ouennoughi, Z.; Hoffmann, A. A new method for evaluating illuminated solar cell parameters. Solid-State Electron. 2001, 45, 293-296. [CrossRef]

19. Abdallah, R.; Natsheh, E.; Juaidi, A.; Samara, S.; Manzano-Agugliaro, F. A Multi-Level World Comprehensive Neural Network Model for Maximum Annual Solar Irradiation on a Flat Surface. Energies 2020, 13, 6422. [CrossRef]

20. Ahmadianfar, I.; Bozorg-Haddad, O.; Chu, X. Gradient-based optimizer: A new Metaheuristic optimization algorithm. Inf. Sci. 2020, 540, 131-159. [CrossRef]

21. Heidari, A.A.; Mirjalili, S.; Faris, H.; Aljarah, I.; Mafarja, M.; Chen, H. Harris hawks optimization: Algorithm and applications. Future Gener. Comput. Syst. 2019, 97, 849-872. [CrossRef]

22. Askari, Q.; Saeed, M.; Younas, I. Heap-based optimizer inspired by corporate rank hierarchy for global optimization. Expert Syst. Appl. 2020, 161, 113702. [CrossRef]

23. Li, S.; Chen, H.; Wang, M.; Heidari, A.A.; Mirjalili, S. Slime mould algorithm: A new method for stochastic optimization. Future Gener. Comput. Syst. 2020, 111, 300-323. [CrossRef]

24. Ismail, M.S.; Moghavvemi, M.; Mahlia, T.M.I. Characterization of PV panel and global optimization of its model parameters using genetic algorithm. Energy Convers. Manag 2013, 73, 10-25. [CrossRef]

25. Ishaque, K.; Salam, Z.; Mekhilef, S.; Shamsudin, A. Parameter extraction of solar photovoltaic modules using penalty-based differential evolution. Appl. Energy 2012, 99, 297-308. [CrossRef]

26. El-Naggar, K.M.; AlRashidi, M.R.; AlHajri, M.F.; Al-Othman, A.K. Simulated annealing algorithm for photovoltaic parameters identification. Sol. Energy 2012, 86, 266-274. [CrossRef]

27. AlHajri, M.F.; El-Naggar, K.M.; AlRashidi, M.R.; Al-Othman, A.K. Optimal extraction of solar cell parameters using pattern search. Renew. Energy 2012, 44, 238-245. [CrossRef]

28. Askarzadeh, A.; Rezazadeh, A. Parameter identification for solar cell models using harmony search-based algorithms. Sol. Energy 2012, 86, 3241-3249. [CrossRef]

29. Ma, J.; Ting, T.O.; Man, K.L.; Zhang, N.; Guan, S.U.; Wong, P.W. Parameter estimation of photovoltaic models via cuckoo search. J. Appl. Math. 2013, 2013, 1-8. [CrossRef]

30. Yousri, D.; Babu, T.S.; Allam, D.; Ramachandaramurthy, V.K.; Beshr, E.; Eteiba, M.B. Fractional Chaos Maps with Flower Pollination Algorithm for Partial Shading Mitigation of Photovoltaic Systems. Energies 2019, 12, 3548. [CrossRef]

31. Subudhi, B.; Pradhan, R. Bacterial foraging optimization approach to parameter extraction of a photovoltaic module. IEEE Trans. Sustain. Energy 2017, 9, 381-389. [CrossRef]

32. Askarzadeh, A.; Rezazadeh, A. Extraction of maximum power point in solar cells using bird mating optimizer-based parameters identification approach. Sol. Energy 2013, 90, 123-133. [CrossRef]

33. Askarzadeh, A.; Rezazadeh, A. Artificial bee swarm optimization algorithm for parameters identification of solar cell models. Appl. Energy 2013, 102, 943-949. [CrossRef]

34. Beigi, A.M.; Maroosi, A. Parameter identification for solar cells and module using a Hybrid Firefly and Pattern Search Algorithms Sol. Energy 2018, 171, 435-446. [CrossRef]

35. Abd Elaziz, M.; Oliva, D. Parameter estimation of solar cells diode models by an improved opposition-based whale optimization algorithm. Energy Convers. Manag 2018, 171, 1843-1859. [CrossRef]

36. Chen, Y.; Chen, Z.; Wu, L.; Long, C.; Lin, P.; Cheng, S. Parameter extraction of PV models using an enhanced shuffled complex evolution algorithm improved by opposition-based learning. Energy Procedia 2019, 158, 991-997. [CrossRef]

37. Mirjalili, S.; Lewis, A. The whale optimization algorithm. Adv. Eng. Softw. 2016, 95, 51. [CrossRef]

38. Eberhart, R.; Kennedy, J. A new optimizer using particle swarm theory. In Proceedings of the Sixth International Symposium on Micro Machine and Human Science, Nagoya, Japan, 4-6 October 1995.

39. Mafarja, M.M.; Mirjalili, S. Hybrid whale optimization algorithm with simulated annealing for feature selection. Neurocomputing 2017, 260, 302-312. [CrossRef]

40. Laskar, N.M.; Guha, K.; Chatterjee, I.; Chanda, S.; Baishnab, K.L.; Paul, P.K. HWPSO: A new hybrid whale-particle swarm optimization algorithm and its application in electronic design optimization problems. Appl. Intell. 2019, 49, 265-291. [CrossRef]

41. Kaur, G.; Arora, S. Chaotic whale optimization algorithm. J. Comput. Des. Eng. 2018, 5, 275-284. [CrossRef]

42. Ling, Y.; Zhou, Y.; Luo, Q. Lévy flight trajectory-based whale optimization algorithm for global optimization. IEEE Access 2017, 5, 6168-6186. [CrossRef]

43. Reddy, K.S.; Panwar, L.; Panigrahi, B.K.; Kumar, R. Binary whale optimization algorithm: A new metaheuristic approach for profit-based unit commitment problems in competitive electricity markets. Eng. Optim. 2019, 51, 369-389. [CrossRef]

44. Pandey, H.M. A Modified Whale Optimization Algorithm with Multi-Objective Criteria for Optimal Robot Path Planning. Available online: http:/ / www.datascience.manchester.ac.uk/media/1669/a-modified-whale-optimization-algorithm-withmulti-objective-criteria-for-optimal-robot-path-planning.pdf (accessed on 26 January 2021).

45. Salgotra, R.; Singh, U.; Saha, S. On some improved versions of whale optimization algorithm. Arab. J. Sci. Eng. 2019, 44, 9653-9691. [CrossRef]

46. Singh, N.; Hachimi, H. A new hybrid whale optimizer algorithm with mean strategy of grey wolf optimizer for global optimization. Math. Comput. Appl. 2018, 23, 14. [CrossRef]

47. Kaveh, A.; Rastegar Moghaddam, M. A hybrid WOA-CBO algorithm for construction site layout planning problem. Sci. Iran. 2018, 25, 1094. [CrossRef] 
48. Xu, Z.; Yu, Y.; Yachi, H.; Ji, J.; Todo, Y.; Gao, S. A novel memetic whale optimization algorithm for optimization. In International Conference on Swarm Intelligence; Springer: Cham, Switzerland, 2018; pp. 384-396.

49. Abd El Aziz, M.; Ewees, A.A.; Hassanien, A.E. Whale optimization algorithm and moth-flame optimization for multilevel thresholding image segmentation. Expert Syst. Appl. 2017, 83, 242-256. [CrossRef]

50. Khalilpourazari, S.; Khalilpourazary, S. SCWOA: An efficient hybrid algorithm for parameter optimization of multi-pass milling process. J. Ind. Prod. Eng. 2018, 35, 135-147. [CrossRef]

51. Bentouati, B.; Chaib, L.; Chettih, S. A hybrid whale algorithm and pattern search technique for optimal power flow problem. In Proceedings of the 8th International Conference on Modelling, Identification and Control (ICMIC), Algiers, Algeria, 1517 November 2016; pp. 1048-1053.

52. Revathi, S.T.; Ramaraj, N.; Chithra, S. Brainstorm-based Whale Optimization Algorithm for privacy-protected data publishing in cloud computing. Clust. Comput. 2019, 22, 3521-3530. [CrossRef]

53. Kang, T.; Yao, J.; Jin, M.; Yang, S.; Duong, T. A Novel Improved Cuckoo Search Algorithm for Parameter Estimation of Photovoltaic (PV) Models. Energies 2018, 11, 1060. [CrossRef]

54. Sheng, H.; Li, C.; Wang, H.; Yan, Z.; Xiong, Y.; Cao, Z.; Kuang, Q. Parameters Extraction of Photovoltaic Models Using an Improved Moth-Flame Optimization. Energies 2019, 12, 3527. [CrossRef]

55. Easwarakhanthan, T.; Bottin, J.; Bouhouch, I.; Boutrit, C. Nonlinear minimization algorithm for determining the solar cell parameters with microcomputers. Int. J. Sol. Energy 1986, 4, 1-12. [CrossRef]

56. Rashedi, E.; Nezamabadi-Pour, H.; Saryazdi, S. GSA: A gravitational search algorithm. Inf. Sci. 2009, 179, 2232. [CrossRef]

57. Mirjalili, S. SCA: A sine cosine algorithm for solving optimization problems. Knowl. Based Syst. 2016, 96, 120-133. [CrossRef]

58. Mirjalili, S.; Mirjalili, S.M.; Lewis, A. Grey wolf optimizer. Adv. Eng. Softw. 2014, 69, 46-61. [CrossRef]

59. Kennedy, J.; Eberhart, R. Particle swarm optimization. In Proceedings of the International Conference on Neural Networks (ICNN'95), Perth, WA, Australia, 27 November-1 December 1995; pp. 1942-1948.

60. Mirjalili, S. Hybrid Particle Swarm Optimization and Gravitational Search Algorithm for Multilayer Perceptron Learning. Ph.D. Thesis, Universiti Teknologi Malaysia, Johor, Malaysia, 2011. 